\title{
Total Syntheses of (+)- and (-)-Cacospongionolide B. New Insight into Structural Requirements for Phospholipase $A_{2}$ Inhibition
}

\author{
Atwood K. Cheung and Marc L. Snapper* \\ Department of Chemistry, Merkert Chemistry Center, Boston College \\ Chestnut Hill, Massachusetts 02467
}

\section{Supporting Information}

General: Starting materials and reagents were purchased from commercial suppliers and used without further purification except the following: diisopropylethylamine, triethylamine, dimethylsulfoxide, and pentane were distilled from $\mathrm{CaH}_{2}$ under anhydrous nitrogen atmosphere; diisopropylcarbodiimide was distilled prior to use; tert-butyl alcohol was distilled from $\mathrm{CaH}_{2}$ and stored over $4 \AA$ MS; methyltriphenylphosphonium bromide was dried in vacuo over $\mathrm{P}_{2} \mathrm{O}_{5}$ for $2 \mathrm{~d}$ prior to use; tetrahydrofuran, diethyl ether, and dichloromethane were dried on alumina columns using a solvent dispensing system; ${ }^{1}$ pentane, hexanes, and ether used in chromatography were distilled prior to use. All reactions were conducted in oven $\left(135^{\circ} \mathrm{C}\right)$ or flame-dried glassware under an inert atmosphere of dry nitrogen.

Infrared (FTIR) spectra were recorded on a Nicolet 210 FT-Infrared spectrophotometer or a Nicolet Avatar 360 spectrophotometer, $v_{\max } \mathrm{cm}^{-1}$. Bands are characterized as broad (br), strong (s), medium (m), and weak (w). Proton nuclear magnetic resonance spectra $\left({ }^{1} \mathbf{H}\right.$ NMR) were recorded on either a Varian Gemini-400 instrument (400 MHz), or a Varian Gemini-500 instrument $(500 \mathrm{MHz})$. Chemical shifts are reported in ppm downfield from tetramethylsilane with the solvent reference as the internal standard $\left(\mathrm{CHCl}_{3}: \delta 7.26 \mathrm{ppm}\right)$. Data is reported as

\footnotetext{
${ }^{1}$ Pangborn, A.B.; Giardello, M.A.; Grubbs, R.H.; Rosen, R.K.; Timmers, F.J. Organometallics 1996, 15, 15181520.
} 
follows: chemical shift, multiplicity ( $\mathrm{s}=$ singlet, $\mathrm{d}=$ doublet, $\mathrm{t}=$ triplet, $\mathrm{q}=$ quartet, $\mathrm{br}=\mathrm{broad}$, $\mathrm{m}=$ multiplet), coupling constants $(\mathrm{Hz})$, and integration. ${ }^{13} \mathbf{C}$ NMR spectra were recorded on either a Varian Gemini-400 instrument (100 MHz), or a Varian Gemini-500 instrument (125 $\mathrm{MHz}$ ) with complete proton decoupling. Chemical shifts are reported in ppm downfield from tetramethylsilane with the solvent as the internal reference $\left(\mathrm{CDCl}_{3}: \delta 77.23 \mathrm{ppm}\right)$. Enantiomeric ratio for compound $\mathbf{1 3}$ was determined by chiral HPLC on a Varian Dynamax HPLC instrument utilizing a Chiralcel OB-H column $(4.6$ x $250 \mathrm{~mm})$ from Chiral Technologies (HPLC conditions: $97.5: 2.5$ hexanes/i-PrOH, $0.75 \mathrm{~mL} / \mathrm{min}, \lambda=250 \mathrm{~nm}$ ). Enantiomeric ratios for compounds 6 and 7 were determined by chiral GC on a Hewlett Packard HP 6890 Series II Gas Chromatograph utilizing either a Beta Dex 120 (30 m x 0.25 mm x $0.25 \mu \mathrm{m}$ film thickness) or Gamma Dex 120 (30 m x $0.25 \mathrm{~mm} \times 0.25 \mu \mathrm{m}$ film thickness) columns from Supelco. Optical rotations were performed on a Rudolph Research Analytical Autopol IV Automatic Polorimeter. Elemental analyses (Anal) were performed by Robertson Microlit Laboratories, Inc. Madison, NJ and are reported in percent abundance. High resolution mass spectral analyses (HRMS) were performed by Mass Spectometry Facility, Boston College.

X-ray data were collected using a Bruker SMART APEX CCD diffactometer with Mo $(\lambda=0.71073 \AA)$ radiation equipped with an LT-3 low-temperature apparatus operating at $183 \mathrm{~K}$. A stable crystal was chosen and mounted on a glass fiber using grease. Data were measured using omega scans of $0.3^{\circ}$ per frame for 30 seconds, such that a hemisphere was collected. A total of 1305 frames were collected with a maximum resolution of $0.75 \AA$. Cell parameters were retrieved using SMART $^{2}$ software and refined using SAINT on all observed reflections. The

\footnotetext{
${ }^{2}$ SMART V 5.050 (NT) Software for the CCD Detector System; Bruker Analytical X-ray Systems, Madison, WI (1998).
} 
structures are solved by the direct method using the SHELXS- $97^{3}$ program and refined by least squares method on $\mathrm{F}^{2}$, SHELXTL-97, ${ }^{4}$ incorporated in SHELXTL-PC V 5.10. ${ }^{5}$ The crystal used for the diffraction study showed no decomposition during data collection. The drawing was displayed at $35 \%$ ellipsoids. The structure was solved by Jarred T. Blank at Boston College.

\section{Experimental Procedures:}

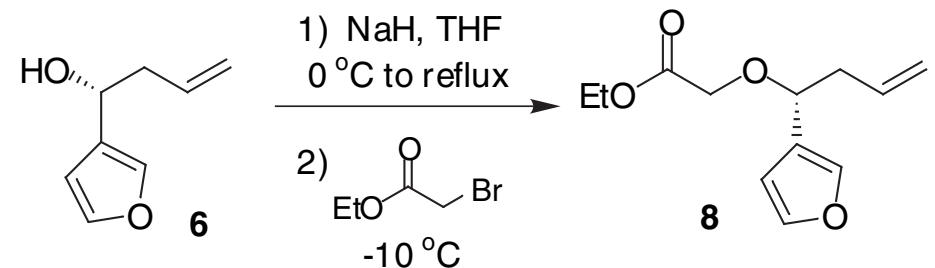

(+)-(1-Furan-3-yl-but-3-enyloxy)-acetic acid ethyl ester (8). To a suspension of sodium hydride (washed previously with dry pentane, $208 \mathrm{mg}, 8.68 \mathrm{mmol}$ ) in THF (25 mL) at $0{ }^{\circ} \mathrm{C}$ was added alcohol $6(800 \mathrm{mg}, 5.79 \mathrm{mmol}, 94 \%$ ee) in THF (5 mL). The reaction was heated to reflux for 30 min until hydrogen evolution ceased, cooled to $-10{ }^{\circ} \mathrm{C}$, and ethyl bromoacetate $(0.963 \mathrm{~mL}, 8.68 \mathrm{mmol})$ in THF $(9 \mathrm{~mL})$ was added dropwise. After stirring at $-10{ }^{\circ} \mathrm{C}$ for $3 \mathrm{~h}$, the reaction mixture was poured into a solution of sat. $\mathrm{NH}_{4} \mathrm{Cl}(50 \mathrm{~mL})$ and extracted with $\mathrm{Et}_{2} \mathrm{O}(4 \times 50 \mathrm{~mL})$. The combined organic extracts were washed with brine, dried over $\mathrm{MgSO}_{4}$, filtered, and concentrated in vacuo. Purification of the residue by chromatography on silica gel (10:1 hexanes/ether) recovered $195 \mathrm{mg}$ of $6(24 \%)$, and afforded $829 \mathrm{mg}$ of compound $8(64 \%)$ as a colorless oil: FTIR (NaCl, thin film) $3131(w), 3075(w), 2987(\mathrm{~m})$, 2911 (m), 1759 (s), 1734 (s), 1508 (m), 1206 (s), 1124 (s), 1023 (m) cm ${ }^{-1} .{ }^{1} \mathbf{H}$ NMR (400 MHz,

\footnotetext{
${ }^{3}$ Sheldrick, G.M. SHELXS-90, Program for the Solution of Crystal Structure, Univeristy of Gottingen, Germany, 1990.

${ }^{4}$ Sheldrick, G.M. SHELXS-97, Program for the Refinement of Crystal Structure, Univeristy of Gottingen, Germany, 1997.

${ }^{5}$ SHELXTL 5.10 (PC-Version), Program Library for Structure Solution and Molecular Graphics; Bruker Analytical X-ray Systems, Madison, WI (1998).
} 
$\left.\mathrm{CDCl}_{3}\right): \delta 1.26(\mathrm{t}, J=7.0 \mathrm{~Hz}, 3 \mathrm{H}), 2.48(\mathrm{dt}, J=14.0,7.0 \mathrm{~Hz}, 1 \mathrm{H}), 2.68(\mathrm{dt}, J=14.0,7.0 \mathrm{~Hz}$ 1H), $3.92(\mathrm{~d}, J=16.4 \mathrm{~Hz}, 1 \mathrm{H}), 4.02(\mathrm{~d}, J=16.4 \mathrm{~Hz}, 1 \mathrm{H}), 4.17(\mathrm{dq}, J=10.8,3.6 \mathrm{~Hz}, 1 \mathrm{H}), 4.20$ $(\mathrm{dq}, J=10.8,3.6 \mathrm{~Hz}, 1 \mathrm{H}), 4.47(\mathrm{t}, J=6.8 \mathrm{~Hz}, 1 \mathrm{H}), 5.04(\mathrm{ddd}, J=10.4,2.4,1.2 \mathrm{~Hz}, 1 \mathrm{H}), 5.10$ (ddd, $J=17.2,3.2,1.6 \mathrm{~Hz}, 1 \mathrm{H}), 5.80(\mathrm{ddd}, J=16.8,14.0,10.0 \mathrm{~Hz}, 1 \mathrm{H}), 6.41$ (s with fine splitting, 1H, Ar), 7.37 (s, 1H, Ar), $7.40(\mathrm{t}, J=1.6 \mathrm{~Hz}, 1 \mathrm{H}, \mathrm{Ar}) .{ }^{13} \mathbf{C}$ NMR $\left(100 \mathrm{MHz}, \mathrm{CDCl}_{3}\right) \delta$ $170.5,143.7,140.7,134.2,124.7,117.3,108.8,74.2,65.5,60.9,40.9,14.5 .[\alpha]_{D}^{20}+70.6(c$ 1.00, EtOH). Anal Calcd for $\mathrm{C}_{12} \mathrm{H}_{16} \mathrm{O}_{4}$ : C, 64.27; H, 7.19. Found: C, 64.50; H, 7.21.

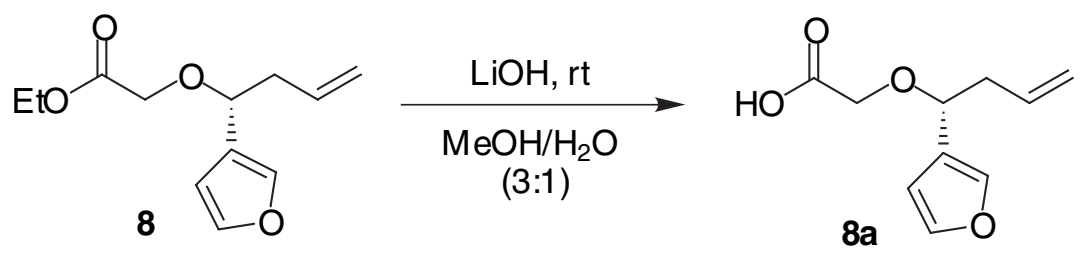

(+)-(1-Furan-3-yl-but-3-enyloxy)-acetic acid (8a). To ester 8 (980 mg, $4.37 \mathrm{mmol})$ in a solution of 3:1 MeOH/H$/ \mathrm{H}_{2} \mathrm{O}(40 \mathrm{~mL})$ was added $\mathrm{LiOH}(520 \mathrm{mg}, 21.9 \mathrm{mmol})$ neat at $0{ }^{\circ} \mathrm{C}$. The reaction was warmed to room temperature (rt) and stirred at this temperature for $12 \mathrm{~h}$. The reaction mixture was then acidified to $\mathrm{pH} 2$ with $20 \% \mathrm{HCl}$, and diluted with $\mathrm{H}_{2} \mathrm{O}(20 \mathrm{~mL})$. The aqueous layer was extracted with ethyl acetate $(4 \times 60 \mathrm{~mL})$. The combined organic layers were washed with $\mathrm{H}_{2} \mathrm{O}$, and brine. The aqueous wash was back-extracted with ethyl acetate, and this organic layer was washed with brine. The organic layers were dried over $\mathrm{MgSO}_{4}$, filtered, and concentrated in vacuo to give $860 \mathrm{mg}$ of compound 8a (100\%) as a colorless oil. The crude material was taken on to the next reaction without further purification: FTIR $(\mathrm{NaCl}$, thin film) 3128 (br), 3072 (m), 2978 (m), 2915 (br), 1736 (s), 1510 (m), 1435 (m), 1128 (s) cm ${ }^{-1}$. ${ }^{1}$ H NMR $\left(400 \mathrm{MHz}, \mathrm{CDCl}_{3}\right): \delta 2.50(\mathrm{dt}, J=14.0,7.0 \mathrm{~Hz}, 1 \mathrm{H}), 2.68(\mathrm{dt}, J=14.0,7.0 \mathrm{~Hz}, 1 \mathrm{H}), 3.97(\mathrm{~d}, J=$ $16.8 \mathrm{~Hz}, 1 \mathrm{H}), 4.07(\mathrm{~d}, J=17.2 \mathrm{~Hz}, 1 \mathrm{H}), 4.46(\mathrm{t}, J=6.8 \mathrm{~Hz}, 1 \mathrm{H}), 5.07$ (d with fine splitting, $J=$ $11.6 \mathrm{~Hz}, 1 \mathrm{H}), 5.11(\mathrm{ddd}, J=16.4,3.2,1.6 \mathrm{~Hz}, 1 \mathrm{H}), 5.77(\mathrm{ddd}, J=17.214 .0,10.0 \mathrm{~Hz}, 1 \mathrm{H}), 6.40$ 
(s with fine splitting, 1H, Ar), 7.39 (s, 1H, Ar), 7.42 (t, J = 1.6 Hz, 1H, Ar), 9.58 (br s, $1 \mathrm{H}) .{ }^{13} \mathbf{C}$ NMR $\left(100 \mathrm{MHz}, \mathrm{CDCl}_{3}\right) \delta 175.4,144.1,141.0,134.1,124.4,118.0,108.8,74.6,65.1,40.8$. $[\alpha]^{20}{ }_{D}+65.0$ (c 1.00, EtOH). Anal Calcd for $\mathrm{C}_{10} \mathrm{H}_{12} \mathrm{O}_{4}: \mathrm{C}, 61.22 ; \mathrm{H}, 6.16$. Found: $\mathrm{C}, 61.36$; $\mathrm{H}$, 6.14
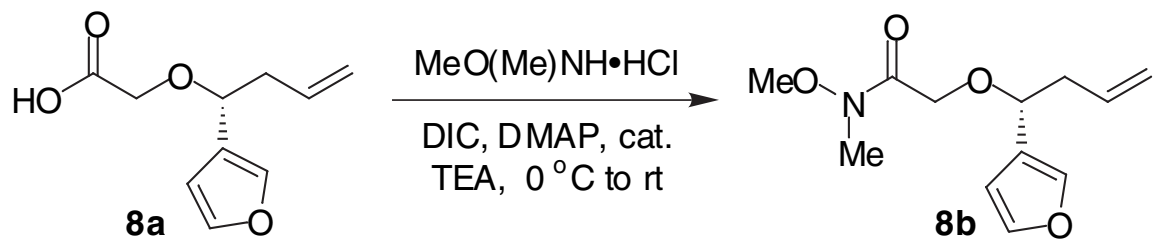

(+)-2-(1-Furan-3-yl-but-3-enyloxy)- $N$-methoxy- $N$-methyl-acetamide $\quad(8 \mathrm{~b}) . \quad$ To a stirring solution of acid $8 \mathbf{a}(1.10 \mathrm{~g}, 5.61 \mathrm{mmol})$ in $\mathrm{CH}_{2} \mathrm{Cl}_{2}(15 \mathrm{~mL})$ was added methoxymethyl amine hydrochloride $(0.656 \mathrm{~g}, 6.73 \mathrm{mmol})$ and dimethylaminopyridine (DMAP) $(0.343 \mathrm{~g}, 2.81$ mmol). The mixture was cooled to $0{ }^{\circ} \mathrm{C}$, and triethylamine (TEA) $(1.10 \mathrm{~mL}, 7.85 \mathrm{mmol})$ followed by diisopropylcarbodiimide (DIC) $(1.23 \mathrm{~mL}, 7.85 \mathrm{mmol})$, were added via syringe. After warming to $\mathrm{rt}$, the reaction was stirred for $4 \mathrm{~h}$, and determined complete by TLC (1:1 hexanes/ethyl acetate). After diluting with brine $(25 \mathrm{~mL})$, the aqueous layer was extracted with ether $/ \mathrm{CH}_{2} \mathrm{Cl}_{2}(1: 1,5 \times 25 \mathrm{~mL})$, and the combined organic layers were dried over $\mathrm{MgSO}_{4}$, filtered, and concentrated in vacuo. The residue was purified by chromatography on silica gel (1:1 hexanes/ethyl acetate) to provide $1.15 \mathrm{~g}$ of compound $\mathbf{8 b}(86 \%)$ as a colorless oil: FTIR $(\mathrm{NaCl}$, thin film) 3122 (w), 3076 (w), 2975 (m), 2939 (m), 1680 (s), 1429 (m), 1085 (m), 995 (m) cm ${ }^{-1}$. ${ }^{1}$ H NMR (400 MHz, $\left.\mathrm{CDCl}_{3}\right): \delta 2.50(\mathrm{dt}, J=14.0,7.0 \mathrm{~Hz}, 1 \mathrm{H}), 2.70(\mathrm{dt}, J=14.0,7.0 \mathrm{~Hz}, 1 \mathrm{H})$, $3.16(\mathrm{~s}, 3 \mathrm{H}), 3.60(\mathrm{~s}, 3 \mathrm{H}), 4.09(\mathrm{~d}, J=15.6 \mathrm{~Hz}, 1 \mathrm{H}), 4.23(\mathrm{~d}, J=16.0 \mathrm{~Hz}, 1 \mathrm{H}), 4.54(\mathrm{t}, J=6.4$ $\mathrm{Hz}, 1 \mathrm{H}$ ), 5.03 (d with fine splitting, $J=10.0 \mathrm{~Hz}, 1 \mathrm{H}$ ), 5.08 (d with fine splitting, $J=17.2 \mathrm{~Hz}$, 1H), 5.81 (ddd, $J=17.2,13.6,10.4 \mathrm{~Hz}, 1 \mathrm{H}$ ), 6.42 (s with fine splitting, 1H, Ar), 7.38 (s, 1H, Ar), 7.41 (s with fine splitting, $1 \mathrm{H}, \mathrm{Ar}) .{ }^{13} \mathbf{C}$ NMR $\left(100 \mathrm{MHz}, \mathrm{CDCl}_{3}\right): \delta 170.9,143.4,140.5$, 
$134.2,124.8,117.1,108.8,73.7,65.0,61.4,40.9,32.3 .[\alpha]^{20}+61.6(c 1.00, \mathrm{EtOH})$. Anal Calcd for $\mathrm{C}_{12} \mathrm{H}_{17} \mathrm{NO}_{4}$ : C, 60.24; H, 7.16; N, 5.85. Found: C, 60.47; H, 7.25; N, 5.88.

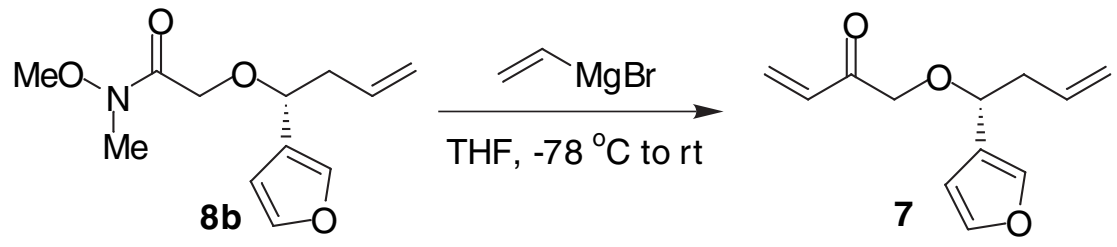

(+)-1-(1-Furan-3-yl-but-3-enyloxy)-but-3-en-2-one (7). To a Schlenk flask (50 mL) charged with a solution of amide $\mathbf{8 b}(873 \mathrm{mg}, 3.65 \mathrm{mmol})$ in THF $(6 \mathrm{~mL})$ at $-78{ }^{\circ} \mathrm{C}$, vinyl magnesium bromide $(9.12 \mathrm{mmol})$ in THF $(10.1 \mathrm{~mL}, 0.9 \mathrm{M})$ was added dropwise. After stirring for $0.5 \mathrm{~h}$, reaction was warmed to $0{ }^{\circ} \mathrm{C}$, and stirred for an additional $1 \mathrm{~h}$ at which time the reaction was determined complete by TLC (1:1 ether/hexanes). The cold reaction mixture was added slowly to a cold, stirring solution of $5 \% \mathrm{NaHSO}_{4}(50 \mathrm{~mL})$. The aqueous layer was extracted with ether $(4 \times 50 \mathrm{~mL})$, and the combined organic extracts were washed with brine, dried over $\mathrm{MgSO}_{4}$, and filtered. The mixture was concentrated in vacuo, and the residue was purified by silica gel chromatography $(5: 1$ pentane/ether). The reaction afforded $625 \mathrm{mg}$ of compound 7 (83\%, 94\% ee) as a colorless oil: FTIR (NaCl, thin film) 3131 (m), 3081 (m), 2974 (m), 2905 (br), 2357 (w), 1697 (s), 1621 (s), 1401 (s) cm ${ }^{-1} .{ }^{1} \mathbf{H}$ NMR (400 MHz, CDCl ${ }_{3}$ ): $\delta 2.49$ $(\mathrm{dt}, J=14.0,7.0 \mathrm{~Hz}, 1 \mathrm{H}), 2.69(\mathrm{dt}, J=14.0,7.0 \mathrm{~Hz}, 1 \mathrm{H}), 4.09(\mathrm{~d}, J=17.2 \mathrm{~Hz}, 1 \mathrm{H}), 4.20(\mathrm{~d}, J=$ $16.8 \mathrm{~Hz}, 1 \mathrm{H}), 4.40(\mathrm{t}, J=6.4 \mathrm{~Hz}, 1 \mathrm{H}), 5.06(\mathrm{~d}$ with fine splitting, $J=10.8 \mathrm{~Hz}, 1 \mathrm{H}), 5.10$ (d with fine splitting, $J=15.6 \mathrm{~Hz}, 1 \mathrm{H}), 5.79(\mathrm{~m}, 2 \mathrm{H}), 6.30(\mathrm{dd}, J=17.6,1.6 \mathrm{~Hz}, 1 \mathrm{H}), 6.40$ (s with fine splitting, 1H, Ar), 6.53 (dd, $J=17.6,10.4 \mathrm{~Hz}, 1 \mathrm{H}), 7.36(\mathrm{~s}, 1 \mathrm{H}, \mathrm{Ar}), 7.41$ (s with fine splitting, 1H, Ar). ${ }^{13} \mathrm{C}$ NMR $\left(100 \mathrm{MHz}, \mathrm{CDCl}_{3}\right): \delta$ 197.2, 143.7, 140.6, 134.1, 132.5, 129.1, 124.8, 117.5, 
108.8, 74.4, 72.3, 41.0. $[\alpha]^{20}{ }_{D}+67.58\left(c\right.$ 1.00, $\left.\mathrm{CHCl}_{3}\right)$. Anal Calcd for $\mathrm{C}_{12} \mathrm{H}_{14} \mathrm{O}_{3}: \mathrm{C}, 69.88 ; \mathrm{H}$, 6.84. Found: C, 69.50; H, 6.67.

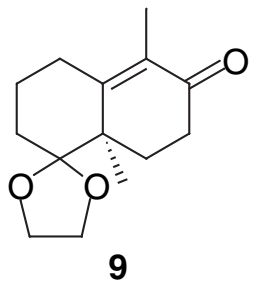

1) $\mathrm{Li} / \mathrm{NH}_{3}, t \mathrm{BuOH}$, 2) $7, \mathrm{Et}_{2} \mathrm{O},-78{ }^{\circ} \mathrm{C}$

(+)-Furanyl diketone (10). To a deep blue solution of lithium $(12.0 \mathrm{mg}, 1.76 \mathrm{mmol})$ in anhydrous liquid ammonia $(10 \mathrm{~mL})$ maintained at $-33{ }^{\circ} \mathrm{C}$ with a dry ice/acetone condenser was added dropwise a solution of enone $9(167 \mathrm{mg}, 0.705 \mathrm{mmol}, 99 \%$ ee) and tert-butyl alcohol $(61.0 \mu \mathrm{L}, 0.635 \mathrm{mmol})$ in diethyl ether $(1.5 \mathrm{~mL})$. After refluxing for $1 \mathrm{~h}$, the reaction was quenched by the addition of several drops of freshly distilled isoprene $\left(\mathrm{Na}^{\circ}\right)$. The ammonia was evaporated at rt over $0.5 \mathrm{~h}$, and the remaining solvent was removed on high vacuum at $40{ }^{\circ} \mathrm{C}$ for $10 \mathrm{~min}$. The residue was then taken up in diethyl ether $(10 \mathrm{~mL})$, and cooled to $-78{ }^{\circ} \mathrm{C}$. The reaction was protected from light. A solution of vinyl ketone 7 (160 mg, $0.776 \mathrm{mmol})$ in diethyl ether ( $3 \mathrm{~mL}$ ) was then added over 20 min via syringe pump to the stirring reaction. After stirring an additional $10 \mathrm{~min}$ at $-78{ }^{\circ} \mathrm{C}$, the reaction was quenched by adding rapidly to a solution of sat. $\mathrm{NH}_{4} \mathrm{Cl}(15 \mathrm{~mL})$. The aqueous layer was extracted with diethyl ether $(4 \times 20 \mathrm{~mL})$, and the combined organic extracts were washed with brine, dried over $\mathrm{MgSO}_{4}$, and filtered. The mixture was concentrated in vacuo, and the residue purified on silica gel prewashed with pyridine $(3: 1$ hexanes/ether). The reaction afforded $198 \mathrm{mg}$ of compound $\mathbf{1 0}(70 \%)$ as a colorless oil: FTIR (NaCl, thin film) 2941 (br), 2882 (br), 1700 (s), 1443 (m), 1131 (m), 1099 (m) cm ${ }^{-1}$. ${ }^{1} \mathbf{H}$ NMR $\left(400 \mathrm{MHz}, \mathrm{CDCl}_{3}\right): \delta 1.04(\mathrm{~s}, 3 \mathrm{H}), 1.21(\mathrm{~s}, 3 \mathrm{H}), 1.43(\mathrm{~m}, 3 \mathrm{H}), 1.53-1.72(\mathrm{~m}, 5 \mathrm{H}), 1.92(\mathrm{~m}, 3 \mathrm{H})$, 
$2.30(\mathrm{~m}, 3 \mathrm{H}), 2.47(\mathrm{dt}, J=13.6,6.8 \mathrm{~Hz}, 1 \mathrm{H}), 2.53(\mathrm{ddd}, J=16.0,13.2,6.8 \mathrm{~Hz}, 1 \mathrm{H}), 2.66(\mathrm{dt}, J$ $=13.6,6.8 \mathrm{~Hz}, 1 \mathrm{H}), 3.91(\mathrm{~m}, 5 \mathrm{H}), 4.00(\mathrm{~d}, J=17.2 \mathrm{~Hz}, 1 \mathrm{H}), 4.36(\mathrm{t}, J=6.8 \mathrm{~Hz}, 1 \mathrm{H}), 5.05(\mathrm{~d}, J$ $=12.4 \mathrm{~Hz}, 1 \mathrm{H}), 5.09(\mathrm{dd}, J=17.2,1.2 \mathrm{~Hz}, 1 \mathrm{H}), 5.80(\mathrm{ddd}, J=17.2,14.0,10.4 \mathrm{~Hz}, 1 \mathrm{H}), 6.40(\mathrm{~s}$ with fine splitting, 1H, Ar), 7.37 (s, $1 \mathrm{H}, \mathrm{Ar}$ ), 7.40 (s with fine splitting, $1 \mathrm{H}, \mathrm{Ar}) .{ }^{13} \mathbf{C}$ NMR (100 $\left.\mathrm{MHz}, \mathrm{CDCl}_{3}\right): \delta 216.2,209.0,143.9,140.8,134.5,125.1,117.7,113.0,109.0,74.5,73.4,65.4$, $65.1,50.5,45.2,42.7,41.0,35.1,35.0,31.0,30.4,29.4,23.0,21.8,21.7,16.7 .[\alpha]^{20}{ }_{D}+40.0(c$ 0.50, $\mathrm{CHCl}_{3}$ ). Anal Calcd for $\mathrm{C}_{26} \mathrm{H}_{36} \mathrm{O}_{6}: \mathrm{C}, 70.24 ; \mathrm{H}, 8.16$. Found: C, 69.90; H, 8.07.

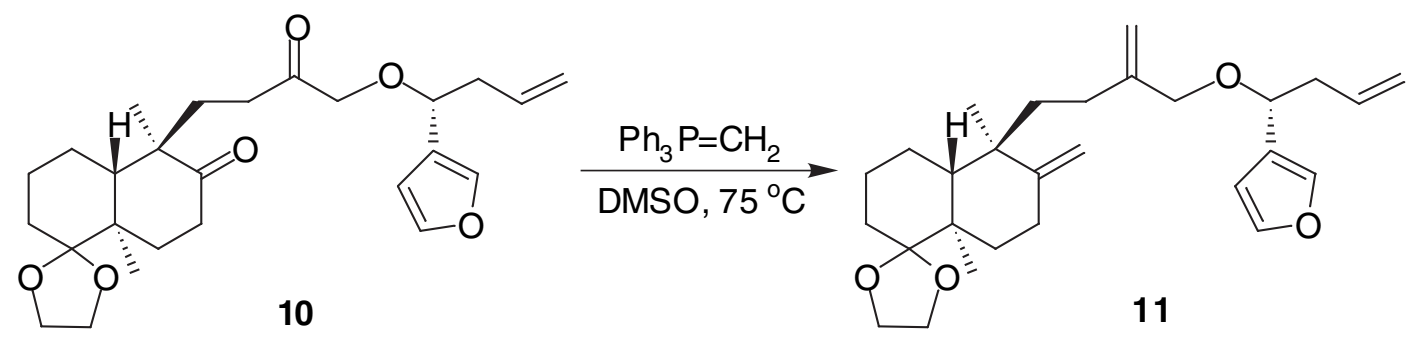

(+)-Triene (11). In a $100 \mathrm{~mL}$, two-neck flask fitted with a reflux condenser, dry sodium hydride $(0.30 \mathrm{~g}, 12.3 \mathrm{mmol})$ was stirred in DMSO $(12 \mathrm{~mL})$ at $75^{\circ} \mathrm{C}$ for $1 \mathrm{~h}$ with a color change from colorless to blue-green signifying the formation of the dimsyl ylide. The solution was cooled to $5{ }^{\circ} \mathrm{C}$, and a solution of methyltriphenylphosphonium bromide $(4.4 \mathrm{~g}, 12.3 \mathrm{mmol})$ in warm DMSO (24 mL) was added dropwise over $30 \mathrm{~min}$. The resulting yellow solution was stirred at $\mathrm{rt}$ for $1 \mathrm{~h}$. The Wittig reagent was titrated to $0.17 \mathrm{M}$ with acetophenone.

The Wittig reagent $(4.5 \mathrm{~mL}, 0.675 \mathrm{mmol})$ and the diketone $10(50 \mathrm{mg}, 0.112 \mathrm{mmol})$ were combined, and stirred at $75^{\circ} \mathrm{C}$ for $2 \mathrm{~h}$. The mixture was then cooled to $\mathrm{rt}$ and quenched by adding rapidly to a solution of sat. $\mathrm{NH}_{4} \mathrm{Cl} / \mathrm{H}_{2} \mathrm{O}(20 \mathrm{~mL})$. The aqueous layer was extracted with diethyl ether $(5 \times 20 \mathrm{~mL})$, and the combined organic layers were washed with brine, dried over $\mathrm{MgSO}_{4}$, and filtered. The mixture was concentrated in vacuo, and the residue purified on basic 
alumina (gradient 9:1, 5:1, 2.5:1, 1:1 hexanes/ether). The reaction afforded $29.5 \mathrm{mg}$ of compound $11(60 \%)$ as a colorless oil: FTIR (NaCl, thin film) 3077 (w), 2982 (m), 2936 (br), 2869 (br), 1632 (m), 1442 (m), 1066 (s) cm ${ }^{-1} .{ }^{1} \mathbf{H}$ NMR (400 MHz, $\mathrm{CDCl}_{3}$ ): $\delta 0.96$ (s, 3H), 1.15 (s, 3H), 1.30-1.71 (m, 10H), $1.72(\mathrm{dd}, J=12.0,2.4 \mathrm{~Hz}, 1 \mathrm{H}), 1.87(\mathrm{~m}, 1 \mathrm{H}), 2.10(\mathrm{~m}, 2 \mathrm{H}), 2.38$ (m, 1H), $2.43(\mathrm{dt}, J=13.5,6.8 \mathrm{~Hz}, 1 \mathrm{H}), 2.59(\mathrm{dt}, J=14.0,7.0 \mathrm{~Hz}, 1 \mathrm{H}), 3.73(\mathrm{~d}, J=12.4 \mathrm{~Hz}$, 1H), 3.81-3.95 (m, 5H), $4.29(\mathrm{t}, J=6.8 \mathrm{~Hz}, 1 \mathrm{H}), 4.59(\mathrm{~s}, 1 \mathrm{H}), 4.74(\mathrm{~s}, 1 \mathrm{H}), 4.89(\mathrm{~s}, 1 \mathrm{H}), 4.94(\mathrm{~s}$, 1H), 5.03 (d with fine splitting, $J=10.0 \mathrm{~Hz}, 1 \mathrm{H}$ ), 5.06 (d with fine splitting, $J=17.2 \mathrm{~Hz}, 1 \mathrm{H}$ ), $5.78(\mathrm{ddd}, J=17.2,14.0,10.0 \mathrm{~Hz}, 1 \mathrm{H}), 6.39$ (s with fine splitting, $1 \mathrm{H}, \mathrm{Ar}$ ), 7.34 (s, 1H, Ar), 7.40 (s with fine splitting, $1 \mathrm{H}, \mathrm{Ar}) .{ }^{13} \mathbf{C}$ NMR $\left(100 \mathrm{MHz}, \mathrm{CDCl}_{3}\right): \delta 154.1,147.4,143.6,140.5$, 134.9, 126.0, 117.3, 113.6, 111.1, 109.1, 106.5, 72.7, 71.3, 65.5, 65.0, 44.2, 43.5, 42.5, 41.3, 37.2, 31.6, 30.6, 29.8, 27.6, 24.6, 23.2, 21.3, 17.7. $[\alpha]^{20}{ }_{\mathrm{D}}+5.86\left(c 0.27, \mathrm{CHCl}_{3}\right)$. Anal Calcd for $\mathrm{C}_{28} \mathrm{H}_{40} \mathrm{O}_{6}$ : C, 76.33; H, 9.15. Found: C, 76.06; H, 9.34.

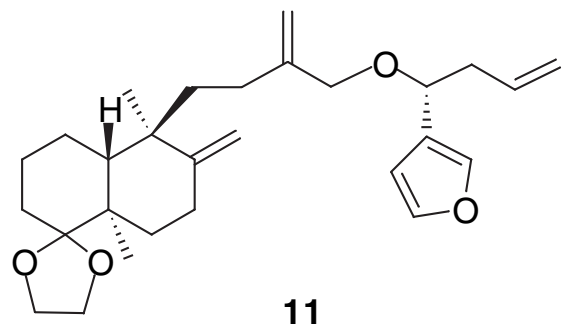

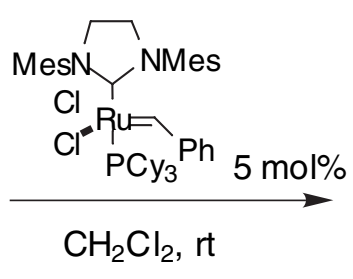

$\mathrm{CH}_{2} \mathrm{Cl}_{2}$, it

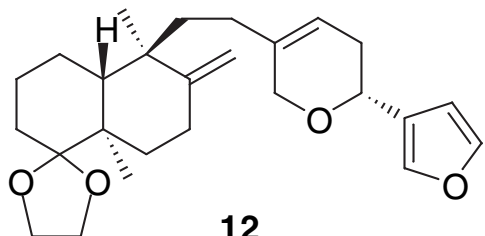

12

(+)-Dienyl furan (12). In a $50 \mathrm{~mL}$ Schlenk flask, triene $11(225 \mathrm{mg}, 0.51 \mathrm{mmol})$ was dissolved in $\mathrm{CH}_{2} \mathrm{Cl}_{2}(20 \mathrm{~mL})$, and the ruthenium catalyst (22 $\left.\mathrm{mg}, 0.026 \mathrm{mmol}\right)$ in $\mathrm{CH}_{2} \mathrm{Cl}_{2}(1 \mathrm{~mL})$ was added. The reaction was stirred at $\mathrm{rt}$ for $14 \mathrm{~h}$, concentrated to an oil, and purified through silica gel chromatography (15:1 hexanes/ether). The reaction afforded $192 \mathrm{mg}$ of compound $\mathbf{1 2}$ (91\%) as a colorless oil: FTIR (NaCl, thin film) 3079 (w), 2936 (br), 2869 (br), 1632 (w), 1063 (s), $876(\mathrm{~m}) \mathrm{cm}^{-1} .{ }^{1} \mathbf{H} \mathbf{N M R}\left(400 \mathrm{MHz}, \mathrm{CDCl}_{3}\right): \delta 0.97(\mathrm{~s}, 3 \mathrm{H}), 1.14(\mathrm{~s}, 3 \mathrm{H}), 1.32-1.80(\mathrm{~m}, 12 \mathrm{H})$, 
$1.95(\mathrm{t}, J=12.8 \mathrm{~Hz}, 1 \mathrm{H}), 2.13(\mathrm{dt}, J=14.0,4.8 \mathrm{~Hz}, 1 \mathrm{H}), 2.22(\mathrm{~m}, 1 \mathrm{H}), 2.35(\mathrm{~m}, 2 \mathrm{H}), 3.87(\mathrm{~m}$, 4H), $4.10(\mathrm{~d}, J=15.6 \mathrm{~Hz}, 1 \mathrm{H}), 4.22$ (d with fine splitting, $J=15.6 \mathrm{~Hz}, 1 \mathrm{H}), 4.49(\mathrm{dd}, J=10.0$, 3.6 Hz, 1H), $4.57(\mathrm{~s}, 1 \mathrm{H}), 4.74(\mathrm{~s}, 1 \mathrm{H}), 5.57$ (br s with fine splitting, 1H), 6.42 (s with fine splitting, 1H, Ar), 7.38 (s with fine splitting, 1H, Ar), 7.40 (s with fine splitting, $1 \mathrm{H}, \mathrm{Ar}$ ). ${ }^{13} \mathbf{C}$ NMR (100 MHz, $\left.\mathrm{CDCl}_{3}\right): \delta 153.9,143.3,139.5,138.0,127.0,117.0,113.6,109.2,106.5,68.9$, $68.7,65.5,65.0,44.1,43.5,42.4,37.0,31.6,31.5,30.6,29.7,27.2,24.6,23.2,21.3,17.6 .[\alpha]^{20}$ + $31.42\left(c\right.$ 0.42, $\left.\mathrm{CHCl}_{3}\right)$. Anal Calcd for $\mathrm{C}_{26} \mathrm{H}_{36} \mathrm{O}_{4}:$ C, 75.60; H, 8.80. Found: C, 75.95; H, 9.05.

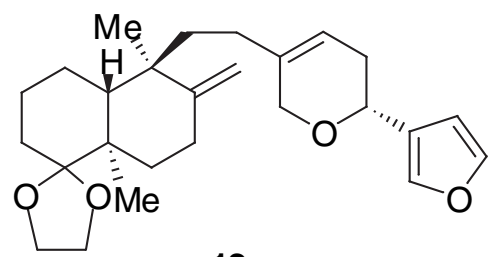

12

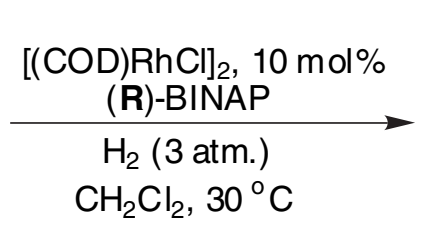

$\mathrm{H}_{2} \mathrm{Cl}_{2}, 30^{\circ} \mathrm{C}$

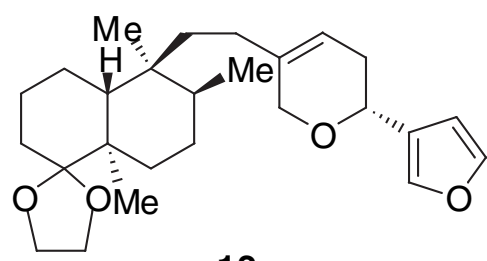

$12 a$

(+)-Furanyl ketal (12a). In a sealed tube with sidearm joint and teflon screwcap, diene 12 (15 mg, $0.036 \mathrm{mmol})$ in $\mathrm{CH}_{2} \mathrm{Cl}_{2}(0.20 \mathrm{~mL})$ was added and mixture degassed twice utilizing a freeze/vacuum/thaw protocol (1. Freeze solution in liquid $\mathrm{N}_{2}$. 2. Place under high vacuum for several seconds, then seal the reaction tube. 3. Thaw the solution, then repeat.) and refilled with nitrogen. In a glovebox, a solution of (R)-BINAP $(5.4 \mathrm{mg}, 0.0086 \mathrm{mmol})$ and $[(\mathrm{COD}) \mathrm{RhCl}]_{2}$ (1.8 $\mathrm{mg}, 0.0036 \mathrm{mmol})$ in $\mathrm{CH}_{2} \mathrm{Cl}_{2}(0.30 \mathrm{~mL})$ was added to the sealed tube. The reaction was degassed three times utilizing the freeze/vacuum/thaw protocol and refilled with hydrogen at $-196{ }^{\circ} \mathrm{C}$ (in liquid $\mathrm{N}_{2}$ ) and sealed. The reaction was stirred at $30{ }^{\circ} \mathrm{C}$ for $6.5 \mathrm{~d}$, opened to air, and concentrated in vacuo. The resulting reside was purified through silica gel chromatography (15: 1 hexanes/ether) to give the desired $\beta$-diastereomer 12a $(8.0 \mathrm{mg})$ and an inseparable mixture of the $\alpha$-diastereomer and the starting material $12(6.0 \mathrm{mg}, 1.5: 1 \mathrm{sm} / \alpha$-diast.). Based on these ratios, the reaction afforded a combined yield of $10.4 \mathrm{mg}$ of compound $\mathbf{1 2 \mathbf { a }}$ and its 
$\alpha$-diastereomer (91\% based on $76 \%$ conversion) as a white solid. The product was recrystallized from acetonitrile to obtain crystals suitable for X-ray crystallography. mp $124-126^{\circ} \mathrm{C}$. FTIR (NaCl, thin film) 3140 (w), 3112 (w), 2955 (s), 2880 (s), 2836 (s), 1453 (m), 1381 (m), 1061 (s) $\mathrm{cm}^{-1} .{ }^{1} \mathbf{H}$ NMR $\left(400 \mathrm{MHz}, \mathrm{CDCl}_{3}\right): \delta 0.89(\mathrm{~s}, 3 \mathrm{H}), 0.95(\mathrm{~d}, J=6.8 \mathrm{~Hz}, 3 \mathrm{H}), 1.09(\mathrm{~m}, 1 \mathrm{H}), 1.10$ (s, 3H), 1.16-1.30 (m, 3H), 1.38-1.93 (m, 12H), 2.18-2.38 (m, 2H), 3.80-4.00 (m, 4H), 4.10 (br d, $J=16.0 \mathrm{~Hz}, 1 \mathrm{H}), 4.23$ (br d with fine splitting, $J=16.0 \mathrm{~Hz}, 1 \mathrm{H}), 4.50(\mathrm{dd}, J=10.0,3.6 \mathrm{~Hz}$, 1H), 5.55 (br s with fine splitting, 1H), 6.42 (s with fine splitting, 1H, Ar), 7.38 (s with fine splitting, 1H, Ar), 7.41 (s with fine splitting, $1 \mathrm{H}, \mathrm{Ar}$ ). ${ }^{13} \mathbf{C}$ NMR (100 $\left.\mathrm{MHz}, \mathrm{CDCl}_{3}\right): \delta 143.1$, 139.3, 138.2, 126.9, 117.1, 113.8, 109.1, 68.9, 68.7, 65.5, 65.1, 44.1, 43.1, 38.4, 37.7, 35.4, 31.7, 30.7, 26.5, 25.2, 24.0, 23.5, 20.7, 20.3, 18.0, 15.0. $[\alpha]^{20}{ }_{\mathrm{D}}+53.99\left(c\right.$ 1.00, $\left.\mathrm{CHCl}_{3}\right)$. Anal Calcd for $\mathrm{C}_{26} \mathrm{H}_{38} \mathrm{O}_{4}$ : C, 75.32; H, 9.24. Found: C, 75.15; H, 8.96.

ORTEP of Compound 12a.

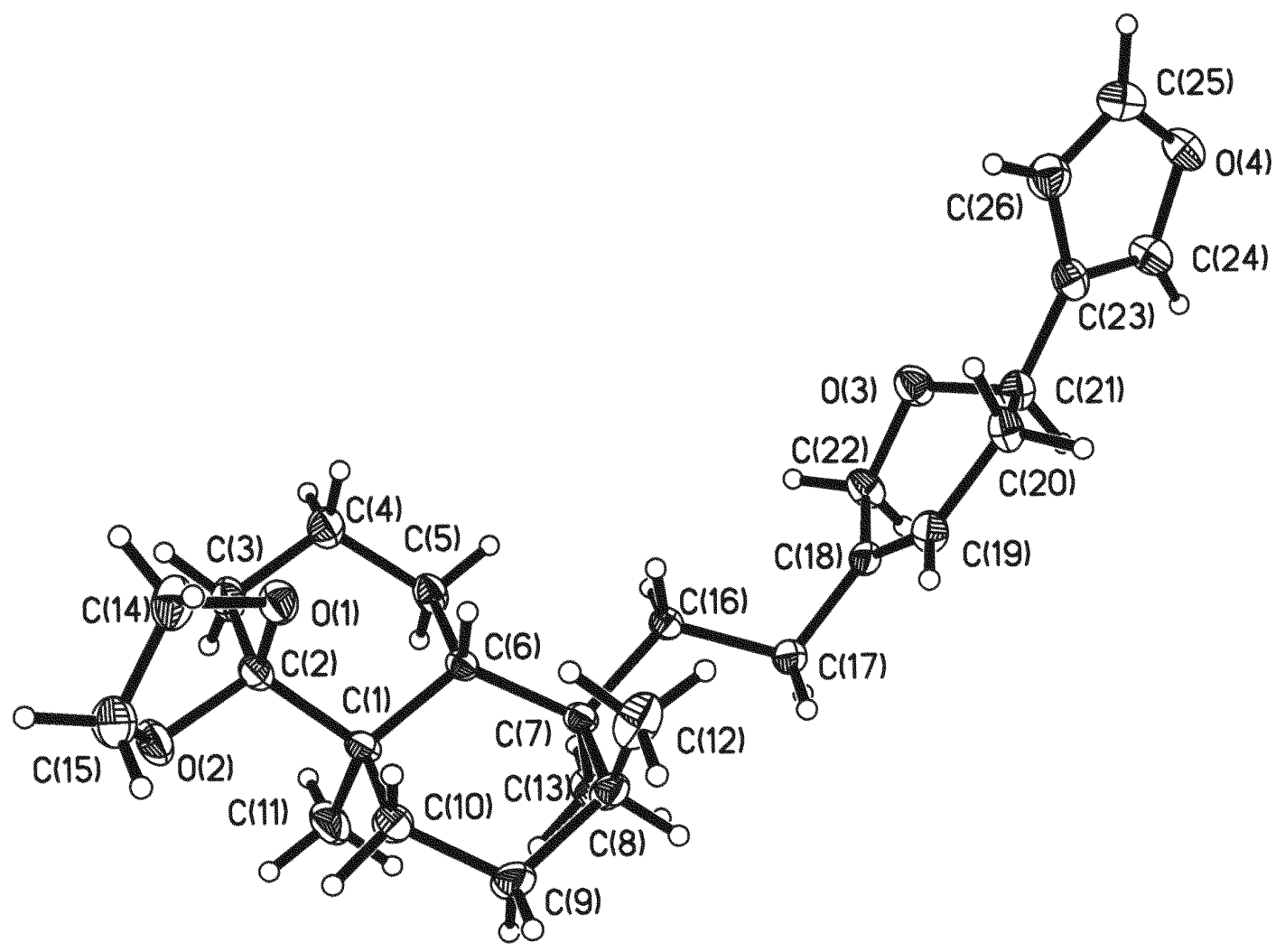


Table 1. Crystal data and structure refinement for compound 12a.

Identification code

Empirical formula

Formula weight

Temperature

Wavelength

Crystal system

Space group

Unit cell dimensions

Volume

Z

Density (calculated)

Absorption coefficient

$\mathrm{F}(000)$

Crystal size

Theta range for data collection

Index ranges

Reflections collected

Independent reflections

Completeness to theta $=28.32^{\circ}$

Absorption correction

Refinement method

Data / restraints / parameters

Goodness-of-fit on $\mathrm{F}^{2}$

Final $R$ indices [I $>2 \operatorname{sigma}(\mathrm{I})]$

$\mathrm{R}$ indices (all data)

Absolute structure parameter

Largest diff. peak and hole akc01a

C26 H38 O4

414.56

183(2) K

$0.71073 \AA$

Monoclinic

P2(1)

$\mathrm{a}=7.6082(11) \AA$

$\alpha=90^{\circ}$.

$\mathrm{b}=11.3828(16) \AA$

$\beta=106.309(3)^{\circ}$.

$\mathrm{c}=13.3218(19) \AA$

$\gamma=90^{\circ}$.

1107.3(3) $\AA^{3}$

2

$1.243 \mathrm{Mg} / \mathrm{m}^{3}$

$0.082 \mathrm{~mm}^{-1}$

452

$0.3 \times 0.25 \times 0.2 \mathrm{~mm}^{3}$

2.40 to $28.32^{\circ}$.

$-9<=\mathrm{h}<=10,-13<=\mathrm{k}<=15,-17<=\mathrm{l}<=16$

8246

$4311[\mathrm{R}(\mathrm{int})=0.0442]$

$99.2 \%$

None

Full-matrix least-squares on $\mathrm{F}^{2}$

$4311 / 1 / 271$

1.033

$\mathrm{R} 1=0.0508, \mathrm{wR} 2=0.1167$

$\mathrm{R} 1=0.0578, \mathrm{wR} 2=0.1200$

$0.4(11)$

0.560 and -0.178 e. $\AA^{3}$

Table 2. Atomic coordinates $\left(\mathrm{x} 10^{4}\right)$ and equivalent isotropic displacement parameters $\left(\AA^{2} \times 10^{3}\right)$

for 12a. $U(e q)$ is defined as one third of the trace of the orthogonalized $U^{i j}$ tensor.

\begin{tabular}{lcrrr}
\hline & $\mathrm{x}$ & $\mathrm{y}$ & $\mathrm{z}$ & $\mathrm{U}(\mathrm{eq})$ \\
\hline $\mathrm{O}(3)$ & $2275(2)$ & $7375(2)$ & $3712(1)$ & $37(1)$ \\
$\mathrm{O}(2)$ & $7276(2)$ & $8419(2)$ & $-2641(1)$ & $39(1)$ \\
$\mathrm{O}(1)$ & $6106(2)$ & $7055(1)$ & $-1741(1)$ & $34(1)$ \\
$\mathrm{C}(16)$ & $5682(3)$ & $8434(2)$ & $1742(2)$ & $25(1)$ \\
$\mathrm{C}(6)$ & $6043(2)$ & $8631(2)$ & $-78(2)$ & $23(1)$ \\
$\mathrm{C}(20)$ & $4698(3)$ & $5980(2)$ & $4421(2)$ & $32(1)$ \\
$\mathrm{O}(4)$ & $-175(2)$ & $5392(2)$ & $5815(1)$ & $40(1)$ \\
$\mathrm{C}(7)$ & $6954(3)$ & $8909(2)$ & $1107(2)$ & $25(1)$ \\
$\mathrm{C}(1)$ & $7247(3)$ & $8855(2)$ & $-829(2)$ & $29(1)$ \\
$\mathrm{C}(18)$ & $5318(3)$ & $7721(2)$ & $3468(2)$ & $26(1)$ \\
$\mathrm{C}(8)$ & $8833(3)$ & $8266(2)$ & $1460(2)$ & $34(1)$ \\
$\mathrm{C}(17)$ & $6451(3)$ & $8455(2)$ & $2944(2)$ & $28(1)$ \\
$\mathrm{C}(23)$ & $1737(3)$ & $6007(2)$ & $4921(2)$ & $32(1)$ \\
$\mathrm{C}(2)$ & $6246(3)$ & $8286(2)$ & $-1892(2)$ & $30(1)$ \\
$\mathrm{C}(3)$ & $4358(3)$ & $8805(2)$ & $-2361(2)$ & $36(1)$ \\
$\mathrm{C}(5)$ & $4138(3)$ & $9184(2)$ & $-524(2)$ & $32(1)$ \\
$\mathrm{C}(10)$ & $9118(3)$ & $8259(3)$ & $-397(2)$ & $42(1)$ \\
$\mathrm{C}(19)$ & $5853(3)$ & $6698(2)$ & $3914(2)$ & $31(1)$ \\
$\mathrm{C}(21)$ & $3165(3)$ & $6727(2)$ & $4622(2)$ & $31(1)$ \\
$\mathrm{C}(25)$ & $-257(3)$ & $4618(2)$ & $5028(2)$ & $41(1)$ \\
& & & &
\end{tabular}


Table 2 (cont). Atomic coordinates $\left(\mathrm{x} 10^{4}\right)$ and equivalent isotropic displacement parameters $\left(\AA^{2} \times 10^{3}\right)$ for 12a. $U(e q)$ is defined as one third of the trace of the orthogonalized $U^{\mathrm{ij}}$ tensor.

\begin{tabular}{lrrrr}
\hline & $\mathrm{x}$ & $\mathrm{y}$ & $\mathrm{z}$ & $\mathrm{U}(\mathrm{eq})$ \\
\hline $\mathrm{C}(22)$ & & & & \\
$\mathrm{C}(4)$ & $3470(3)$ & $8208(2)$ & $3453(2)$ & $33(1)$ \\
$\mathrm{C}(12)$ & $3179(3)$ & $8691(2)$ & $-1612(2)$ & $36(1)$ \\
$\mathrm{C}(9)$ & $7221(4)$ & $10223(2)$ & $1339(2)$ & $38(1)$ \\
$\mathrm{C}(13)$ & $10030(3)$ & $8565(3)$ & $747(2)$ & $49(1)$ \\
$\mathrm{C}(14)$ & $8711(3)$ & $6941(2)$ & $1557(2)$ & $45(1)$ \\
$\mathrm{C}(26)$ & $6559(4)$ & $6458(2)$ & $-2567(2)$ & $44(1)$ \\
$\mathrm{C}(15)$ & $860(3)$ & $4953(2)$ & $4456(2)$ & $42(1)$ \\
$\mathrm{C}(11)$ & $7827(4)$ & $7289(3)$ & $-2889(2)$ & $48(1)$ \\
$\mathrm{C}(24)$ & $7551(4)$ & $10156(2)$ & $-1042(2)$ & $49(1)$ \\
& $1055(3)$ & $6225(2)$ & $5726(2)$ & $38(1)$ \\
\hline
\end{tabular}

Table 3. Bond lengths $[\AA]$ and angles $\left[{ }^{\circ}\right]$ for 12a.

\begin{tabular}{ll}
\hline $\mathrm{O}(3)-\mathrm{C}(21)$ & $1.417(3)$ \\
$\mathrm{O}(3)-\mathrm{C}(22)$ & $1.422(3)$ \\
$\mathrm{O}(2)-\mathrm{C}(15)$ & $1.420(3)$ \\
$\mathrm{O}(2)-\mathrm{C}(2)$ & $1.439(3)$ \\
$\mathrm{O}(1)-\mathrm{C}(14)$ & $1.416(3)$ \\
$\mathrm{O}(1)-\mathrm{C}(2)$ & $1.424(3)$ \\
$\mathrm{C}(16)-\mathrm{C}(17)$ & $1.542(3)$ \\
$\mathrm{C}(16)-\mathrm{C}(7)$ & $1.551(3)$ \\
$\mathrm{C}(6)-\mathrm{C}(5)$ & $1.538(3)$ \\
$\mathrm{C}(6)-\mathrm{C}(1)$ & $1.556(3)$ \\
$\mathrm{C}(6)-\mathrm{C}(7)$ & $1.567(3)$ \\
$\mathrm{C}(20)-\mathrm{C}(19)$ & $1.494(3)$ \\
$\mathrm{C}(20)-\mathrm{C}(21)$ & $1.526(3)$ \\
$\mathrm{O}(4)-\mathrm{C}(25)$ & $1.356(3)$ \\
$\mathrm{O}(4)-\mathrm{C}(24)$ & $1.360(3)$ \\
$\mathrm{C}(7)-\mathrm{C}(12)$ & $1.530(3)$ \\
$\mathrm{C}(7)-\mathrm{C}(8)$ & $1.556(3)$ \\
$\mathrm{C}(1)-\mathrm{C}(10)$ & $1.536(3)$ \\
$\mathrm{C}(1)-\mathrm{C}(11)$ & $1.537(3)$ \\
$\mathrm{C}(1)-\mathrm{C}(2)$ & $1.549(3)$ \\
$\mathrm{C}(18)-\mathrm{C}(19)$ & $1.318(3)$ \\
$\mathrm{C}(18)-\mathrm{C}(22)$ & $1.506(3)$ \\
$\mathrm{C}(18)-\mathrm{C}(17)$ & $1.507(3)$ \\
$\mathrm{C}(8)-\mathrm{C}(13)$ & $1.520(4)$ \\
$\mathrm{C}(8)-\mathrm{C}(9)$ & $1.527(3)$ \\
$\mathrm{C}(23)-\mathrm{C}(24)$ & $1.339(3)$ \\
$\mathrm{C}(23)-\mathrm{C}(26)$ & $1.427(4)$ \\
$\mathrm{C}(23)-\mathrm{C}(21)$ & $1.501(3)$ \\
$\mathrm{C}(2)-\mathrm{C}(3)$ & $1.516(3)$ \\
$\mathrm{C}(3)-\mathrm{C}(4)$ & $1.522(3)$ \\
$\mathrm{C}(5)-\mathrm{C}(4)$ & $1.535(3)$ \\
$\mathrm{C}(10)-\mathrm{C}(9)$ & $1.527(3)$ \\
$\mathrm{C}(25)-\mathrm{C}(26)$ & $1.345(4)$ \\
$\mathrm{C}(14)-\mathrm{C}(15)$ & $1.497(4)$ \\
$\mathrm{C}(21)-\mathrm{O}(3)-\mathrm{C}(22)$ & \\
$\mathrm{C}(15)-\mathrm{O}(2)-\mathrm{C}(2)$ & $11.72(17)$ \\
& $108.67(18)$ \\
& \\
& \\
& \\
&
\end{tabular}


Table 3 (cont). Bond lengths $[\AA]$ and angles $\left[{ }^{\circ}\right]$ for $\mathbf{1 2 a}$.

\begin{tabular}{|c|c|}
\hline $\mathrm{C}(14)-\mathrm{O}(1)-\mathrm{C}(2)$ & $108.55(17)$ \\
\hline$C(17)-C(16)-C(7)$ & $116.62(16)$ \\
\hline$C(5)-C(6)-C(1)$ & $110.23(17)$ \\
\hline$C(5)-C(6)-C(7)$ & $114.11(16)$ \\
\hline $\mathrm{C}(1)-\mathrm{C}(6)-\mathrm{C}(7)$ & $116.15(15)$ \\
\hline $\mathrm{C}(19)-\mathrm{C}(20)-\mathrm{C}(21)$ & $110.51(19)$ \\
\hline $\mathrm{C}(25)-\mathrm{O}(4)-\mathrm{C}(24)$ & $105.59(19)$ \\
\hline$C(12)-C(7)-C(16)$ & $107.34(17)$ \\
\hline$C(12)-C(7)-C(8)$ & $109.89(18)$ \\
\hline $\mathrm{C}(16)-\mathrm{C}(7)-\mathrm{C}(8)$ & $109.38(18)$ \\
\hline $\mathrm{C}(12)-\mathrm{C}(7)-\mathrm{C}(6)$ & $113.40(18)$ \\
\hline$C(16)-C(7)-C(6)$ & $108.17(15)$ \\
\hline $\mathrm{C}(8)-\mathrm{C}(7)-\mathrm{C}(6)$ & $108.58(16)$ \\
\hline$C(10)-C(1)-C(11)$ & $108.9(2)$ \\
\hline $\mathrm{C}(10)-\mathrm{C}(1)-\mathrm{C}(2)$ & $108.90(19)$ \\
\hline $\mathrm{C}(11)-\mathrm{C}(1)-\mathrm{C}(2)$ & $107.19(19)$ \\
\hline$C(10)-C(1)-C(6)$ & $109.69(18)$ \\
\hline$C(11)-C(1)-C(6)$ & $115.03(19)$ \\
\hline$C(2)-C(1)-C(6)$ & $106.96(16)$ \\
\hline $\mathrm{C}(19)-\mathrm{C}(18)-\mathrm{C}(22)$ & $120.07(19)$ \\
\hline C(19)-C(18)-C(17) & $123.65(19)$ \\
\hline $\mathrm{C}(22)-\mathrm{C}(18)-\mathrm{C}(17)$ & $116.27(18)$ \\
\hline $\mathrm{C}(13)-\mathrm{C}(8)-\mathrm{C}(9)$ & $109.6(2)$ \\
\hline $\mathrm{C}(13)-\mathrm{C}(8)-\mathrm{C}(7)$ & $114.80(18)$ \\
\hline $\mathrm{C}(9)-\mathrm{C}(8)-\mathrm{C}(7)$ & $111.4(2)$ \\
\hline $\mathrm{C}(18)-\mathrm{C}(17)-\mathrm{C}(16)$ & 111.91(16) \\
\hline $\mathrm{C}(24)-\mathrm{C}(23)-\mathrm{C}(26)$ & $105.3(2)$ \\
\hline $\mathrm{C}(24)-\mathrm{C}(23)-\mathrm{C}(21)$ & $125.7(2)$ \\
\hline $\mathrm{C}(26)-\mathrm{C}(23)-\mathrm{C}(21)$ & $129.0(2)$ \\
\hline $\mathrm{O}(1)-\mathrm{C}(2)-\mathrm{O}(2)$ & $106.17(17)$ \\
\hline $\mathrm{O}(1)-\mathrm{C}(2)-\mathrm{C}(3)$ & $109.99(18)$ \\
\hline $\mathrm{O}(2)-\mathrm{C}(2)-\mathrm{C}(3)$ & $108.12(18)$ \\
\hline $\mathrm{O}(1)-\mathrm{C}(2)-\mathrm{C}(1)$ & $108.68(17)$ \\
\hline $\mathrm{O}(2)-\mathrm{C}(2)-\mathrm{C}(1)$ & $111.42(17)$ \\
\hline$C(3)-C(2)-C(1)$ & $112.28(19)$ \\
\hline$C(2)-C(3)-C(4)$ & $111.18(18)$ \\
\hline $\mathrm{C}(4)-\mathrm{C}(5)-\mathrm{C}(6)$ & $111.19(18)$ \\
\hline $\mathrm{C}(9)-\mathrm{C}(10)-\mathrm{C}(1)$ & $112.8(2)$ \\
\hline $\mathrm{C}(18)-\mathrm{C}(19)-\mathrm{C}(20)$ & $122.7(2)$ \\
\hline $\mathrm{O}(3)-\mathrm{C}(21)-\mathrm{C}(23)$ & $107.64(18)$ \\
\hline $\mathrm{O}(3)-\mathrm{C}(21)-\mathrm{C}(20)$ & $110.20(18)$ \\
\hline $\mathrm{C}(23)-\mathrm{C}(21)-\mathrm{C}(20)$ & $112.8(2)$ \\
\hline $\mathrm{C}(26)-\mathrm{C}(25)-\mathrm{O}(4)$ & $110.8(2)$ \\
\hline $\mathrm{O}(3)-\mathrm{C}(22)-\mathrm{C}(18)$ & $114.14(19)$ \\
\hline $\mathrm{C}(3)-\mathrm{C}(4)-\mathrm{C}(5)$ & $112.12(19)$ \\
\hline $\mathrm{C}(8)-\mathrm{C}(9)-\mathrm{C}(10)$ & $112.76(18)$ \\
\hline $\mathrm{O}(1)-\mathrm{C}(14)-\mathrm{C}(15)$ & $103.7(2)$ \\
\hline $\mathrm{C}(25)-\mathrm{C}(26)-\mathrm{C}(23)$ & $106.6(2)$ \\
\hline $\mathrm{O}(2)-\mathrm{C}(15)-\mathrm{C}(14)$ & $104.4(2)$ \\
\hline $\mathrm{C}(23)-\mathrm{C}(24)-\mathrm{O}(4)$ & $111.8(2)$ \\
\hline
\end{tabular}

Symmetry transformations used to generate equivalent atoms: 
Table 4. Anisotropic displacement parameters $\left(\AA^{2} \times 10^{3}\right)$ for 12a. The anisotropic displacement factor exponent takes the form: $-2 \pi^{2}\left[h^{2} a^{* 2} U^{11}+\ldots+2 h k a^{*} b^{*} U^{12}\right]$

\begin{tabular}{|c|c|c|c|c|c|c|}
\hline & $\mathrm{U}^{11}$ & $\mathrm{U}^{22}$ & $\mathrm{U}^{33}$ & $\mathrm{U}^{23}$ & $\mathrm{U}^{13}$ & $\mathrm{U}^{12}$ \\
\hline $\mathrm{O}(3)$ & $33(1)$ & $39(1)$ & $40(1)$ & 11(1) & $12(1)$ & $3(1)$ \\
\hline $\mathrm{O}(2)$ & $47(1)$ & $44(1)$ & $34(1)$ & $-4(1)$ & $25(1)$ & $-5(1)$ \\
\hline $\mathrm{O}(1)$ & $46(1)$ & $28(1)$ & $32(1)$ & $-5(1)$ & $16(1)$ & $-4(1)$ \\
\hline$C(16)$ & $22(1)$ & $31(1)$ & $25(1)$ & $-2(1)$ & $9(1)$ & $-1(1)$ \\
\hline$C(6)$ & $23(1)$ & $23(1)$ & $25(1)$ & $-2(1)$ & 11(1) & $-2(1)$ \\
\hline $\mathrm{C}(20)$ & $35(1)$ & $34(1)$ & $28(1)$ & $7(1)$ & $12(1)$ & $8(1)$ \\
\hline $\mathrm{O}(4)$ & $43(1)$ & $38(1)$ & $44(1)$ & $5(1)$ & $22(1)$ & $-1(1)$ \\
\hline$C(7)$ & $24(1)$ & $26(1)$ & $26(1)$ & $-4(1)$ & 11(1) & $-5(1)$ \\
\hline $\mathrm{C}(1)$ & $28(1)$ & $34(1)$ & $29(1)$ & $-5(1)$ & $15(1)$ & $-10(1)$ \\
\hline $\mathrm{C}(18)$ & $25(1)$ & $31(1)$ & $21(1)$ & $-2(1)$ & $6(1)$ & $-2(1)$ \\
\hline C(8) & $20(1)$ & $51(2)$ & $29(1)$ & $-12(1)$ & $7(1)$ & $0(1)$ \\
\hline $\mathrm{C}(17)$ & $26(1)$ & $33(1)$ & $25(1)$ & $-2(1)$ & $8(1)$ & $-3(1)$ \\
\hline $\mathrm{C}(23)$ & $35(1)$ & $29(1)$ & $34(1)$ & $7(1)$ & $12(1)$ & $7(1)$ \\
\hline$C(2)$ & $34(1)$ & $31(1)$ & $28(1)$ & $-1(1)$ & $15(1)$ & $-8(1)$ \\
\hline$C(3)$ & $40(1)$ & $42(1)$ & $26(1)$ & $6(1)$ & $10(1)$ & 2(1) \\
\hline $\mathrm{C}(5)$ & $29(1)$ & $39(1)$ & $30(1)$ & $6(1)$ & $14(1)$ & 7(1) \\
\hline $\mathrm{C}(10)$ & $25(1)$ & $70(2)$ & $34(1)$ & $-14(1)$ & $15(1)$ & $-6(1)$ \\
\hline $\mathrm{C}(19)$ & $27(1)$ & $38(1)$ & $28(1)$ & 2(1) & $10(1)$ & 7(1) \\
\hline $\mathrm{C}(21)$ & $34(1)$ & $34(1)$ & $27(1)$ & 1(1) & $10(1)$ & 1(1) \\
\hline$C(25)$ & $37(1)$ & $36(1)$ & $51(2)$ & $-1(1)$ & $14(1)$ & $-4(1)$ \\
\hline$C(22)$ & $33(1)$ & $30(1)$ & $39(1)$ & $8(1)$ & $16(1)$ & $4(1)$ \\
\hline C(4) & $27(1)$ & $49(2)$ & $30(1)$ & $7(1)$ & 7(1) & 6(1) \\
\hline $\mathrm{C}(12)$ & $54(1)$ & $29(1)$ & $37(1)$ & $-10(1)$ & $22(1)$ & $-12(1)$ \\
\hline $\mathrm{C}(9)$ & $21(1)$ & $89(2)$ & $37(1)$ & $-17(1)$ & $10(1)$ & $-10(1)$ \\
\hline C(13) & $40(1)$ & $52(2)$ & $39(1)$ & $-8(1)$ & $3(1)$ & $20(1)$ \\
\hline$C(14)$ & $57(2)$ & $41(2)$ & $34(1)$ & $-7(1)$ & $14(1)$ & $3(1)$ \\
\hline$C(26)$ & $44(1)$ & $46(2)$ & $38(1)$ & $-4(1)$ & $13(1)$ & $-1(1)$ \\
\hline$C(15)$ & $51(2)$ & $56(2)$ & $43(2)$ & $-16(1)$ & $23(1)$ & $-4(1)$ \\
\hline$C(11)$ & $70(2)$ & $44(2)$ & $42(1)$ & $-6(1)$ & $29(1)$ & $-28(1)$ \\
\hline$C(24)$ & $42(1)$ & $33(1)$ & $44(1)$ & $-1(1)$ & $20(1)$ & $-3(1)$ \\
\hline
\end{tabular}


Table 5. Hydrogen coordinates ( $\left.\mathrm{x} 10^{4}\right)$ and isotropic displacement parameters $\left(\AA^{2} \times 10^{3}\right)$ for 12a.

\begin{tabular}{|c|c|c|c|c|}
\hline & $\mathrm{x}$ & $\mathrm{y}$ & z & $\mathrm{U}(\mathrm{eq})$ \\
\hline $\mathrm{H}(16 \mathrm{~A})$ & 4559 & 8888 & 1553 & 30 \\
\hline $\mathrm{H}(16 \mathrm{~B})$ & 5364 & 7629 & 1528 & 30 \\
\hline $\mathrm{H}(6 \mathrm{~A})$ & 5828 & 7781 & -106 & 27 \\
\hline $\mathrm{H}(20 \mathrm{~A})$ & 5453 & 5667 & 5078 & 38 \\
\hline $\mathrm{H}(20 \mathrm{~B})$ & 4173 & 5324 & 3972 & 38 \\
\hline $\mathrm{H}(8 \mathrm{~A})$ & 9469 & 8566 & 2157 & 40 \\
\hline $\mathrm{H}(17 \mathrm{~A})$ & 7698 & 8162 & 3138 & 33 \\
\hline $\mathrm{H}(17 \mathrm{~B})$ & 6478 & 9260 & 3188 & 33 \\
\hline $\mathrm{H}(3 \mathrm{~A})$ & 3766 & 8403 & -3010 & 43 \\
\hline $\mathrm{H}(3 \mathrm{~B})$ & 4474 & 9628 & -2519 & 43 \\
\hline $\mathrm{H}(5 \mathrm{~A})$ & 3394 & 9025 & -55 & 38 \\
\hline $\mathrm{H}(5 \mathrm{~B})$ & 4262 & 10029 & -569 & 38 \\
\hline $\mathrm{H}(10 \mathrm{~A})$ & 8959 & 7414 & -462 & 50 \\
\hline $\mathrm{H}(10 \mathrm{~B})$ & 9917 & 8495 & -814 & 50 \\
\hline $\mathrm{H}(19 \mathrm{~A})$ & 6998 & 6412 & 3912 & 37 \\
\hline $\mathrm{H}(21 \mathrm{~A})$ & 3700 & 7280 & 5189 & 38 \\
\hline $\mathrm{H}(25 \mathrm{~A})$ & -985 & 3948 & 4902 & 49 \\
\hline $\mathrm{H}(22 \mathrm{~A})$ & 3644 & 8858 & 3942 & 39 \\
\hline $\mathrm{H}(22 \mathrm{~B})$ & 2889 & 8517 & 2760 & 39 \\
\hline $\mathrm{H}(4 \mathrm{~A})$ & 2892 & 7869 & -1548 & 43 \\
\hline $\mathrm{H}(4 \mathrm{~B})$ & 2036 & 9108 & -1899 & 43 \\
\hline $\mathrm{H}(12 \mathrm{~A})$ & 7788 & 10336 & 2073 & 57 \\
\hline $\mathrm{H}(12 \mathrm{~B})$ & 6053 & 10610 & 1143 & 57 \\
\hline $\mathrm{H}(12 \mathrm{C})$ & 7989 & 10548 & 948 & 57 \\
\hline $\mathrm{H}(9 \mathrm{~A})$ & 11177 & 8140 & 984 & 58 \\
\hline H(9B) & 10307 & 9398 & 802 & 58 \\
\hline $\mathrm{H}(13 \mathrm{~A})$ & 9923 & 6615 & 1779 & 68 \\
\hline $\mathrm{H}(13 \mathrm{~B})$ & 8064 & 6614 & 892 & 68 \\
\hline $\mathrm{H}(13 \mathrm{C})$ & 8069 & 6755 & 2063 & 68 \\
\hline $\mathrm{H}(14 \mathrm{~A})$ & 5475 & 6309 & -3142 & 52 \\
\hline $\mathrm{H}(14 \mathrm{~B})$ & 7163 & 5718 & -2329 & 52 \\
\hline $\mathrm{H}(26 \mathrm{~A})$ & 1027 & 4572 & 3872 & 50 \\
\hline $\mathrm{H}(15 \mathrm{~A})$ & 9090 & 7134 & -2505 & 58 \\
\hline $\mathrm{H}(15 \mathrm{~B})$ & 7700 & 7224 & -3632 & 58 \\
\hline $\mathrm{H}(11 \mathrm{~A})$ & 8317 & 10214 & -1504 & 74 \\
\hline $\mathrm{H}(11 \mathrm{~B})$ & 8134 & 10545 & -395 & 74 \\
\hline $\mathrm{H}(11 \mathrm{C})$ & 6392 & 10523 & -1362 & 74 \\
\hline $\mathrm{H}(24 \mathrm{~A})$ & 1382 & 6867 & 6171 & 46 \\
\hline
\end{tabular}


Table 6. Torsion angles $\left[{ }^{\circ}\right]$ for $\mathbf{1 2 a}$.

\begin{tabular}{|c|c|}
\hline $\mathrm{C}(17)-\mathrm{C}(16)-\mathrm{C}(7)-\mathrm{C}(12)$ & $-65.8(2)$ \\
\hline $\mathrm{C}(17)-\mathrm{C}(16)-\mathrm{C}(7)-\mathrm{C}(8)$ & $53.3(2)$ \\
\hline $\mathrm{C}(17)-\mathrm{C}(16)-\mathrm{C}(7)-\mathrm{C}(6)$ & $171.45(18)$ \\
\hline$C(5)-C(6)-C(7)-C(12)$ & $-59.3(2)$ \\
\hline$C(1)-C(6)-C(7)-C(12)$ & $70.6(2)$ \\
\hline$C(5)-C(6)-C(7)-C(16)$ & $59.6(2)$ \\
\hline$C(1)-C(6)-C(7)-C(16)$ & $-170.47(18)$ \\
\hline $\mathrm{C}(5)-\mathrm{C}(6)-\mathrm{C}(7)-\mathrm{C}(8)$ & 178.21(18) \\
\hline $\mathrm{C}(1)-\mathrm{C}(6)-\mathrm{C}(7)-\mathrm{C}(8)$ & $-51.9(2)$ \\
\hline$C(5)-C(6)-C(1)-C(10)$ & $-177.80(18)$ \\
\hline$C(7)-C(6)-C(1)-C(10)$ & $50.4(2)$ \\
\hline$C(5)-C(6)-C(1)-C(11)$ & $59.1(2)$ \\
\hline$C(7)-C(6)-C(1)-C(11)$ & $-72.7(3)$ \\
\hline $\mathrm{C}(5)-\mathrm{C}(6)-\mathrm{C}(1)-\mathrm{C}(2)$ & $-59.8(2)$ \\
\hline$C(7)-C(6)-C(1)-C(2)$ & $168.40(18)$ \\
\hline$C(12)-C(7)-C(8)-C(13)$ & $163.6(2)$ \\
\hline $\mathrm{C}(16)-\mathrm{C}(7)-\mathrm{C}(8)-\mathrm{C}(13)$ & $46.0(2)$ \\
\hline $\mathrm{C}(6)-\mathrm{C}(7)-\mathrm{C}(8)-\mathrm{C}(13)$ & $-71.8(2)$ \\
\hline $\mathrm{C}(12)-\mathrm{C}(7)-\mathrm{C}(8)-\mathrm{C}(9)$ & $-71.1(2)$ \\
\hline $\mathrm{C}(16)-\mathrm{C}(7)-\mathrm{C}(8)-\mathrm{C}(9)$ & 171.32(19) \\
\hline$C(6)-C(7)-C(8)-C(9)$ & $53.5(2)$ \\
\hline$C(19)-C(18)-C(17)-C(16)$ & $107.0(2)$ \\
\hline $\mathrm{C}(22)-\mathrm{C}(18)-\mathrm{C}(17)-\mathrm{C}(16)$ & $-72.2(2)$ \\
\hline $\mathrm{C}(7)-\mathrm{C}(16)-\mathrm{C}(17)-\mathrm{C}(18)$ & $-166.25(18)$ \\
\hline $\mathrm{C}(14)-\mathrm{O}(1)-\mathrm{C}(2)-\mathrm{O}(2)$ & $-15.9(2)$ \\
\hline $\mathrm{C}(14)-\mathrm{O}(1)-\mathrm{C}(2)-\mathrm{C}(3)$ & $100.8(2)$ \\
\hline $\mathrm{C}(14)-\mathrm{O}(1)-\mathrm{C}(2)-\mathrm{C}(1)$ & $-135.87(19)$ \\
\hline $\mathrm{C}(15)-\mathrm{O}(2)-\mathrm{C}(2)-\mathrm{O}(1)$ & $-3.1(2)$ \\
\hline $\mathrm{C}(15)-\mathrm{O}(2)-\mathrm{C}(2)-\mathrm{C}(3)$ & $-121.1(2)$ \\
\hline $\mathrm{C}(15)-\mathrm{O}(2)-\mathrm{C}(2)-\mathrm{C}(1)$ & $115.1(2)$ \\
\hline $\mathrm{C}(10)-\mathrm{C}(1)-\mathrm{C}(2)-\mathrm{O}(1)$ & $56.6(2)$ \\
\hline $\mathrm{C}(11)-\mathrm{C}(1)-\mathrm{C}(2)-\mathrm{O}(1)$ & $174.21(19)$ \\
\hline $\mathrm{C}(6)-\mathrm{C}(1)-\mathrm{C}(2)-\mathrm{O}(1)$ & $-61.9(2)$ \\
\hline $\mathrm{C}(10)-\mathrm{C}(1)-\mathrm{C}(2)-\mathrm{O}(2)$ & $-60.1(2)$ \\
\hline $\mathrm{C}(11)-\mathrm{C}(1)-\mathrm{C}(2)-\mathrm{O}(2)$ & $57.6(2)$ \\
\hline $\mathrm{C}(6)-\mathrm{C}(1)-\mathrm{C}(2)-\mathrm{O}(2)$ & $-178.56(18)$ \\
\hline $\mathrm{C}(10)-\mathrm{C}(1)-\mathrm{C}(2)-\mathrm{C}(3)$ & $178.5(2)$ \\
\hline $\mathrm{C}(11)-\mathrm{C}(1)-\mathrm{C}(2)-\mathrm{C}(3)$ & $-63.9(2)$ \\
\hline$C(6)-C(1)-C(2)-C(3)$ & $60.0(2)$ \\
\hline $\mathrm{O}(1)-\mathrm{C}(2)-\mathrm{C}(3)-\mathrm{C}(4)$ & $64.2(2)$ \\
\hline $\mathrm{O}(2)-\mathrm{C}(2)-\mathrm{C}(3)-\mathrm{C}(4)$ & 179.74(19) \\
\hline $\mathrm{C}(1)-\mathrm{C}(2)-\mathrm{C}(3)-\mathrm{C}(4)$ & $-56.9(3)$ \\
\hline $\mathrm{C}(1)-\mathrm{C}(6)-\mathrm{C}(5)-\mathrm{C}(4)$ & $58.0(2)$ \\
\hline $\mathrm{C}(7)-\mathrm{C}(6)-\mathrm{C}(5)-\mathrm{C}(4)$ & $-169.17(18)$ \\
\hline $\mathrm{C}(11)-\mathrm{C}(1)-\mathrm{C}(10)-\mathrm{C}(9)$ & $76.0(3)$ \\
\hline $\mathrm{C}(2)-\mathrm{C}(1)-\mathrm{C}(10)-\mathrm{C}(9)$ & $-167.4(2)$ \\
\hline $\mathrm{C}(6)-\mathrm{C}(1)-\mathrm{C}(10)-\mathrm{C}(9)$ & $-50.7(3)$ \\
\hline $\mathrm{C}(22)-\mathrm{C}(18)-\mathrm{C}(19)-\mathrm{C}(20)$ & $-0.2(3)$ \\
\hline $\mathrm{C}(17)-\mathrm{C}(18)-\mathrm{C}(19)-\mathrm{C}(20)$ & $-179.4(2)$ \\
\hline $\mathrm{C}(21)-\mathrm{C}(20)-\mathrm{C}(19)-\mathrm{C}(18)$ & $-16.2(3)$ \\
\hline $\mathrm{C}(22)-\mathrm{O}(3)-\mathrm{C}(21)-\mathrm{C}(23)$ & $171.75(19)$ \\
\hline $\mathrm{C}(22)-\mathrm{O}(3)-\mathrm{C}(21)-\mathrm{C}(20)$ & $-64.8(2)$ \\
\hline $\mathrm{C}(24)-\mathrm{C}(23)-\mathrm{C}(21)-\mathrm{O}(3)$ & $-105.9(3)$ \\
\hline $\mathrm{C}(26)-\mathrm{C}(23)-\mathrm{C}(21)-\mathrm{O}(3)$ & $76.2(3)$ \\
\hline $\mathrm{C}(24)-\mathrm{C}(23)-\mathrm{C}(21)-\mathrm{C}(20)$ & $132.3(2)$ \\
\hline
\end{tabular}


Table 6 (cont). Torsion angles $\left[{ }^{\circ}\right]$ for $\mathbf{1 2 a}$.

\begin{tabular}{lc}
\hline $\mathrm{C}(26)-\mathrm{C}(23)-\mathrm{C}(21)-\mathrm{C}(20)$ & $-45.6(3)$ \\
$\mathrm{C}(19)-\mathrm{C}(20)-\mathrm{C}(21)-\mathrm{O}(3)$ & $47.7(3)$ \\
$\mathrm{C}(19)-\mathrm{C}(20)-\mathrm{C}(21)-\mathrm{C}(23)$ & $168.07(18)$ \\
$\mathrm{C}(24)-\mathrm{O}(4)-\mathrm{C}(25)-\mathrm{C}(26)$ & $-0.7(3)$ \\
$\mathrm{C}(21)-\mathrm{O}(3)-\mathrm{C}(22)-\mathrm{C}(18)$ & $47.3(3)$ \\
$\mathrm{C}(19)-\mathrm{C}(18)-\mathrm{C}(22)-\mathrm{O}(3)$ & $-14.3(3)$ \\
$\mathrm{C}(17)-\mathrm{C}(18)-\mathrm{C}(22)-\mathrm{O}(3)$ & $164.95(18)$ \\
$\mathrm{C}(2)-\mathrm{C}(3)-\mathrm{C}(4)-\mathrm{C}(5)$ & $52.5(3)$ \\
$\mathrm{C}(6)-\mathrm{C}(5)-\mathrm{C}(4)-\mathrm{C}(3)$ & $-53.6(3)$ \\
$\mathrm{C}(13)-\mathrm{C}(8)-\mathrm{C}(9)-\mathrm{C}(10)$ & $70.3(3)$ \\
$\mathrm{C}(7)-\mathrm{C}(8)-\mathrm{C}(9)-\mathrm{C}(10)$ & $-57.8(3)$ \\
$\mathrm{C}(1)-\mathrm{C}(10)-\mathrm{C}(9)-\mathrm{C}(8)$ & $56.5(3)$ \\
$\mathrm{C}(2)-\mathrm{O}(1)-\mathrm{C}(14)-\mathrm{C}(15)$ & $27.5(3)$ \\
$\mathrm{O}(4)-\mathrm{C}(25)-\mathrm{C}(26)-\mathrm{C}(23)$ & $0.9(3)$ \\
$\mathrm{C}(24)-\mathrm{C}(23)-\mathrm{C}(26)-\mathrm{C}(25)$ & $-0.8(3)$ \\
$\mathrm{C}(21)-\mathrm{C}(23)-\mathrm{C}(26)-\mathrm{C}(25)$ & $177.5(2)$ \\
$\mathrm{C}(2)-\mathrm{O}(2)-\mathrm{C}(15)-\mathrm{C}(14)$ & $19.5(2)$ \\
$\mathrm{O}(1)-\mathrm{C}(14)-\mathrm{C}(15)-\mathrm{O}(2)$ & $-28.5(3)$ \\
$\mathrm{C}(26)-\mathrm{C}(23)-\mathrm{C}(24)-\mathrm{O}(4)$ & $0.4(3)$ \\
$\mathrm{C}(21)-\mathrm{C}(23)-\mathrm{C}(24)-\mathrm{O}(4)$ & $-178.0(2)$ \\
$\mathrm{C}(25)-\mathrm{O}(4)-\mathrm{C}(24)-\mathrm{C}(23)$ & $0.2(3)$ \\
& \\
\hline
\end{tabular}

Symmetry transformations used to generate equivalent atoms:

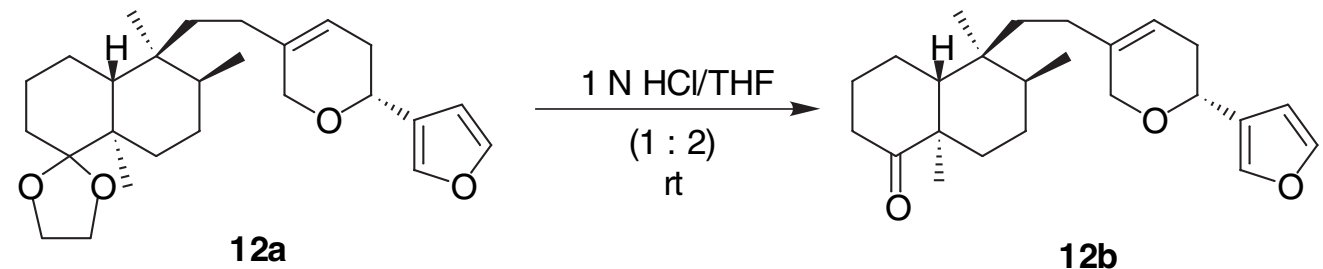

(+)-Furanyl ketone (12b). The ketal 12a (13 mg, $0.029 \mathrm{mmol})$ was stirred in $1 \mathrm{~N}$ $\mathrm{HCl} / \mathrm{THF}(1: 2,0.50 \mathrm{~mL})$ at $\mathrm{rt}$ for $16 \mathrm{~h}$. The mixture was diluted with ether, and washed consecutively with water, sat. $\mathrm{NaHCO}_{3}$, and brine. The organic layer was dried over $\mathrm{MgSO}_{4}$, filtered, and concentrated in vacuo. The resulting residue was purified through silica gel chromatography (10:1 hexanes/ether) to afford $10.5 \mathrm{mg}$ of compound $\mathbf{1 2 b}(90 \%)$ as a white solid: mp 79-82 ${ }^{\circ} \mathrm{C}$. FTIR (NaCl, thin film) 2936 (s), 2873 (m), 1704 (s), 1502 (w), 1455 (m), $1383(\mathrm{~m}), 1159(\mathrm{~m}), 1069(\mathrm{~m}), 1025(\mathrm{~m}), 882(\mathrm{~m}) \mathrm{cm}^{-1} .{ }^{1} \mathbf{H} \mathbf{N M R}\left(400 \mathrm{MHz}, \mathrm{CDCl}_{3}\right): \delta 0.90(\mathrm{~d}$, $J=7.2 \mathrm{~Hz}, 3 \mathrm{H}), 1.00(\mathrm{~s}, 3 \mathrm{H}), 1.15(\mathrm{~m}, 1 \mathrm{H}), 1.19(\mathrm{~s}, 3 \mathrm{H}), 1.28(\mathrm{~m}, 2 \mathrm{H}), 1.36(\mathrm{dd}, J=11.2,3.0$ 
$\mathrm{Hz}, 2 \mathrm{H}), 1.46-1.92(\mathrm{~m}, 8 \mathrm{H}), 2.07(\mathrm{~m}, 1 \mathrm{H}), 2.17-2.39(\mathrm{~m}, 3 \mathrm{H}), 2.58(\mathrm{td}, J=13.6,7.2 \mathrm{~Hz}, 1 \mathrm{H})$, $4.11(\mathrm{br} \mathrm{d}, J=16.0 \mathrm{~Hz}, 1 \mathrm{H}), 4.23$ (br d with fine splitting, $J=16.8 \mathrm{~Hz}, 1 \mathrm{H}$ ), 4.50 (dd, $J=9.6$, 3.6 Hz, 1H), 5.57 (br s with fine splitting, 1H), 6.42 (s with fine splitting, 1H, Ar), 7.39 (s with fine splitting, $1 \mathrm{H}, \mathrm{Ar}$ ), 7.41 (s with fine splitting, $1 \mathrm{H}, \mathrm{Ar}) .{ }^{13} \mathbf{C} \mathbf{~ N M R}\left(125 \mathrm{MHz}, \mathrm{CDCl}_{3}\right)$ : $\delta 216.0,143.4,139.5,138.0,127.0,118.0,109.1,68.9,68.5,49.5,47.5,38.7,38.2,37.7,35.0$, $31.5,26.4,26.3,26.1,24.8,21.0,20.3,19.8,14.6 .[\alpha]^{20}{ }_{D}+61.32\left(c 0.60, \mathrm{CHCl}_{3}\right)$. HRMS (ESI+) $\mathrm{m} / \mathrm{z}$ calcd for $\mathrm{C}_{24} \mathrm{H}_{34} \mathrm{O}_{3} \mathrm{Na}$ : 393.2406. Found: 393.2410 .

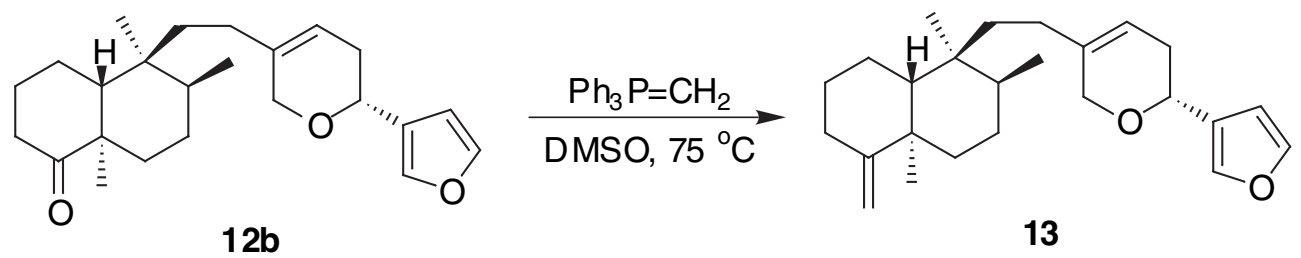

(+)-Furan (13). The Wittig solution was prepared as described in the preparation of compound 11. Ketone 12b $(13.4 \mathrm{mg}, 0.036 \mathrm{mmol})$ was stirred with the Wittig solution $(1.2 \mathrm{~mL})$ at $75{ }^{\circ} \mathrm{C}$ for $1 \mathrm{~h}$. The reaction was quenched by adding rapidly to sat. $\mathrm{NH}_{4} \mathrm{Cl} / \mathrm{H}_{2} \mathrm{O}(5 \mathrm{~mL})$, and extracted with ether $(4 \times 5 \mathrm{~mL})$. The combined organic layers were washed with brine, dried over $\mathrm{MgSO}_{4}$, and filtered. The mixture was concentrated in vacuo, and purified through silica gel chromatography (20:1 hexanes/ether) to afford $11.1 \mathrm{mg}$ of compound $\mathbf{1 3}(84 \%)$ as a white solid: mp 36-39 ${ }^{\circ} \mathrm{C}$. FTIR (NaCl, thin film) 3083 (w), 2936 (s), 2868 (m), 1628 (w), 1450 (m), $1377(\mathrm{~m}), 1152(\mathrm{~m}) \mathrm{cm}^{-1} .{ }^{1} \mathbf{H}$ NMR $\left(400 \mathrm{MHz}, \mathrm{CDCl}_{3}\right): \delta 0.92(\mathrm{~d}, J=7.2 \mathrm{~Hz}, 3 \mathrm{H}), 0.93(\mathrm{~s}, 3 \mathrm{H})$, $1.08(\mathrm{~m}, 1 \mathrm{H}), 1.10(\mathrm{~s}, 3 \mathrm{H}), 1.17(\mathrm{dd}, J=12.0,2.4 \mathrm{~Hz}, 1 \mathrm{H}), 1.20-1.53(\mathrm{~m}, 5 \mathrm{H}), 1.60(\mathrm{~m}, 2 \mathrm{H})$, 1.76-1.91 (m, 4H), $1.99(\mathrm{tt}, J=13.8,3.6 \mathrm{~Hz}, 1 \mathrm{H}), 2.09$ (d with fine splitting, $J=13.6 \mathrm{~Hz}, 1 \mathrm{H}$ ), 2.17-2.39 (m, 3H), $4.11(\mathrm{br} \mathrm{d}, J=16.0 \mathrm{~Hz}, 1 \mathrm{H}), 4.23$ (br d with fine splitting, $J=16.0 \mathrm{~Hz}, 1 \mathrm{H}$ ), $4.48(\mathrm{~s}, 1 \mathrm{H}), 4.50(\mathrm{~m}, 1 \mathrm{H}), 4.52(\mathrm{~s}, 1 \mathrm{H}), 5.56$ (br s with fine splitting, 1H), 6.42 (s with fine 
splitting, 1H, Ar), 7.38 (s with fine splitting, $1 \mathrm{H}, \mathrm{Ar}$ ), 7.40 (s with fine splitting, $1 \mathrm{H}, \mathrm{Ar}$ ). ${ }^{13} \mathrm{C}$ NMR $\left(125 \mathrm{MHz}, \mathrm{CDCl}_{3}\right): \delta 160.8,143.3,139.5,138.3,127.0,117.3,109.1,102.2,68.9,68.6$, $48.1,40.6,38.2,38.1,35.7,33.1,31.6,30.4,28.9,26.3,25.8,21.51,21.50,20.7,15.0 .[\alpha]^{20}{ }_{D}+$ 92.61 ( c 0.76, $\mathrm{CHCl}_{3}$ ). Anal Calcd for $\mathrm{C}_{25} \mathrm{H}_{36} \mathrm{O}_{2}: \mathrm{C}, 81.47 ; \mathrm{H}, 9.85$. Found: C, 81.42; H, 9.98.

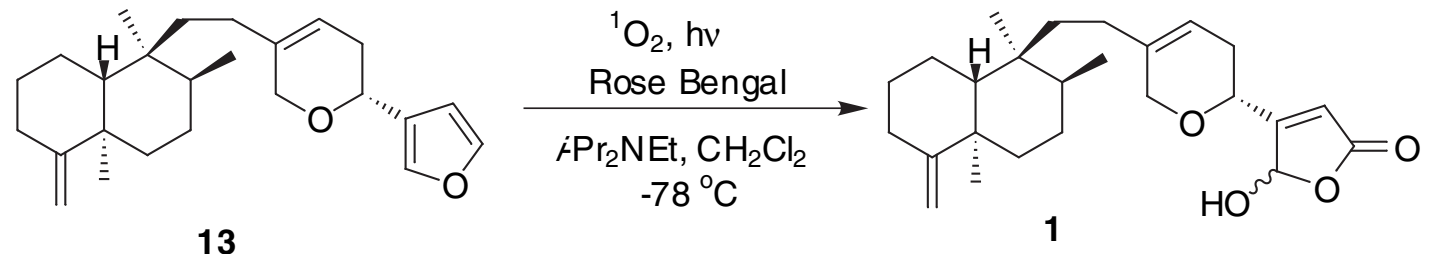

(+)-Cacospongionolide B (1). To a flask charged with rose bengal $(0.8 \mathrm{mg}, 0.0008$ mmol) was added furan $\mathbf{1 3}(6.0 \mathrm{mg}, 0.016 \mathrm{mmol})$ in a solution of $\mathrm{CH}_{2} \mathrm{Cl}_{2}(3.2 \mathrm{~mL})$, followed by $i$ - $\mathrm{Pr}_{2} \mathrm{NEt}(14 \mu \mathrm{L}, 0.08 \mathrm{mmol})$. The bright red reaction was cooled to $-78^{\circ} \mathrm{C}$, and irradiated with a $150 \mathrm{~W}$ tungsten lamp while anhydrous $\mathrm{O}_{2}$ was bubbled through the solution for $8 \mathrm{~min}$. The irradiation continued for a total of $1 \mathrm{~h}$ under a blanket of anhydrous $\mathrm{O}_{2}$. The reaction was then protected from light, and warmed to rt under $\mathrm{N}_{2}$. Sat. aqueous oxalic acid $(3 \mathrm{~mL})$ was added, and the mixture stirred until colorless (15 min). The aqueous layer was extracted with $\mathrm{CH}_{2} \mathrm{Cl}_{2}(3 \times 5$ $\mathrm{mL}$ ), and the combined organic layers were dried over $\mathrm{MgSO}_{4}$, and filtered. The mixture was concentrated in vacuo, and the resulting residue was purified through silica gel chromatography (1:1 hexanes/ether) to provide cacospongionolde B (1) (4.4 mg, 69\%, white solid) as a mixture of diastereomers that was identical to an authentic sample provided by Dr. S. De Rosa: mp 135$140{ }^{\circ} \mathrm{C}$. FTIR (NaCl, thin film) 3340 (br), 3082 (w), 2930 (s), 2867 (m), 2850 (m), 1756 (s), 1742 (s), 1637 (w), 1452 (m), 1380 (m), 1130 (m), 942 (m) cm ${ }^{-1} .{ }^{1} \mathbf{H}$ NMR (400 MHz, $\mathrm{CDCl}_{3}$ ): $\delta 0.91(\mathrm{~d}, J=7.2 \mathrm{~Hz}, 3 \mathrm{H}), 0.93(\mathrm{~s}, 3 \mathrm{H}), 1.06(\mathrm{~m}, 1 \mathrm{H}), 1.10(\mathrm{~s}, 3 \mathrm{H}), 1.16(\mathrm{dd}, J=12.4,2.0 \mathrm{~Hz}$, $1 \mathrm{H}), 1.23-1.51(\mathrm{~m}, 5 \mathrm{H}), 1.55-1.63(\mathrm{~m}, 2 \mathrm{H}), 1.76-1.91(\mathrm{~m}, 4 \mathrm{H}), 1.99(\mathrm{tt}, J=14.0,3.2 \mathrm{~Hz}, 1 \mathrm{H})$, 
$2.10(\mathrm{dd}, J=13.6,4.0 \mathrm{~Hz}, 1 \mathrm{H}), 2.18-2.38(\mathrm{~m}, 3 \mathrm{H}), 3.70(\mathrm{br} \mathrm{s}, 1 \mathrm{H}), 4.17(\mathrm{~m}, 2 \mathrm{H}), 4.40$ (ddd, $J=$ 9.6, 4.4, $1.2 \mathrm{~Hz}, 0.5 \mathrm{H}), 4.42$ (ddd, $J=10.0,4.4,1.6 \mathrm{~Hz}, 0.5 \mathrm{H}), 4.49$ (s, 1H), 4.52 (s, 1H), 5.55

(br s, 1H), 6.02 (s with fine splitting, 0.5H), 6.09 (s with fine splitting, 1H), $6.23\left(\mathrm{~s}, 0.5 \mathrm{H}\right.$ ). ${ }^{13} \mathrm{C}$ NMR $\left(125 \mathrm{MHz}, \mathrm{CDCl}_{3}\right): \delta 170.3,167.7,167.0,138.6,138.3,118.7,117.7,116.2,116.0,102.3$, 97.6, 97.1, 70.1, 69.3, 68.7, 68.6, 48.1, 40.6, 38.2, 38.1, 35.7, 33.1, 30.4, 29.9, 29.6, 29.1, 28.9, 26.3, 25.8, 21.5, 20.7, 15.0. $[\alpha]^{20}{ }_{\mathrm{D}}+124.0\left(\mathrm{c} 0.25, \mathrm{CHCl}_{3}\right)$. HRMS (ESI+) $\mathrm{m} / \mathrm{z}$ calcd for $\mathrm{C}_{25} \mathrm{H}_{36} \mathrm{O}_{4} \mathrm{Na}: 423.2511$. Found: 423.2522 .

Assay of the Inhibition of Bee Venom $s \mathbf{P L A}_{2}$. The $\mathrm{IC}_{50}$ values for compounds (+)-1, $(-)-\mathbf{1}, \mathbf{2},(+)-\mathbf{1 3}$, and (-)-13 were determined using $s \mathrm{PLA}_{2}$ Assay Kit obtained from Cayman Chemical, Ann Arbor, MI (Cat. No. 765001), and UV data recorded on a Molecular Devices Thermomax microplate reader. Manoalide was obtained from BIOMOL Research Laboratories Inc., Plymouth Meeting, PA. Following the assay procedure, the initial rates of hydrolysis for a series of substrates with final concentrations from 400-0.5 $\mu \mathrm{M}(400,200,100,50,25,12.5,5$, $2.5,1,0.5 \mu \mathrm{M})$ were obtained, and percent inhibition was calculated compared to a control. The percent inhibition was plotted verses the $\log \left[\right.$ inhibitor], and the $\mathrm{IC}_{50}$ was extrapolated from the resulting curves. The values reported are the average of 3-4 measurements with error bars representing plus and minus one standard deviation unit.

\section{Bee Venom $s$ PLA 2 Inhibition:}

\begin{tabular}{lc}
\hline \multicolumn{1}{c}{ Inhibitor } & IC $_{50}$ \\
\hline manoalide (2) & $38( \pm 3) \mu \mathrm{M}$ \\
(+)-cacospongionolide B (1) & $49( \pm 9) \mu \mathrm{M}$ \\
(-)-cacospongionolide B (1) & $114( \pm 7) \mu \mathrm{M}$ \\
(+)-furan (13) & $71( \pm 4) \mu \mathrm{M}$ \\
(-)-furan (13) & $167( \pm 32) \mu \mathrm{M}$ \\
\hline
\end{tabular}

